Review

\title{
Towards a Predictive Simulation of Turbulent Combustion?-An Assessment for Large Internal Combustion Engines
}

\author{
Thomas Lauer *(i) and Jens Frühhaber
}

Citation: Lauer, T.; Frühhaber, J.

Towards a Predictive Simulation of Turbulent Combustion?-An

Assessment for Large Internal

Combustion Engines. Energies 2021,

14, 43. https://dx.doi.org/10.3390/ en14010043

\section{Received: 20 October 2020}

Accepted: 16 December 2020

Published: 23 December 2020

Publisher's Note: MDPI stays neutral with regard to jurisdictional claims in published maps and institutional affiliations.

Copyright: () 2020 by the authors. Licensee MDPI, Basel, Switzerland. This article is an open access article distributed under the terms and conditions of the Creative Commons Attribution (CC BY) license (https: / / creativecommons.org/ licenses/by/4.0/).
Institute of Powertrains and Automotive Technology, TU Wien, 1060 Vienna, Austria; jens.fruehhaber@ifa.tuwien.ac.at

* Correspondence: thomas.lauer@ifa.tuwien.ac.at; Tel.: +43-1-58801-31575

\begin{abstract}
Frequently the question arises in what sense numerical simulation can be considered predictive if prior model tuning with test results is necessary. In this paper a summary of the present Computational Fluid Dynamics (CFD) simulation methods for in-cylinder modelling is presented with a focus on combustion processes relevant for large engines. The current discussion about the sustainability of internal combustion engines will have a strong impact on applying advanced CFD methods in industrial processes. It is therefore included in the assessment. Simplifications and assumptions of turbulence, spray, and combustion models, as well as uncertainties of model boundary conditions, are discussed and the future potential of an advanced approach like Large Eddy Simulation (LES) is evaluated. It follows that a high amount of expertise and a careful evaluation of the numerical results will remain necessary in the future to apply the best-suited models for a given combustion process. New chemical mechanisms will have to be developed in order to represent prospective fuels like hydrogen or OME. Multi-injection or dual fuel combustion will further pose high requirements to the numerical methods. Therefore, the further development and validation of advanced mixture, combustion and emission models will remain important. Close cooperation between academia, code suppliers and engine manufacturers could promote the necessary progress.
\end{abstract}

Keywords: internal combustion engines; large engines; turbulence; computational fluid dynamics; LES; combustion; spray; emissions

\section{Introduction}

Numerical simulation has become an indispensable part of the development process of internal combustion engines over the years. Particularly in an early phase when no hardware for testing is available, detailed numerical investigations provide first information on mixture preparation and combustion. However, the stringent future targets and requirements for internal combustion engines (ICE) with respect to efficiency and emissions are putting pressure on numerical methods to provide more and more detailed and accurate results of the complete combustion process. From this follows that accurate models must be available for all physicochemical processes of turbulent combustion and pollutant formation.

The most detailed and therefore predictive approach for combustion and pollutant modelling is provided by the CFD simulation (Computational fluid dynamics). However, though many simulation results were successfully validated against experimental data, the model transfer to a different engine with a different combustion process usually needs further model adaption to accomplish a good correlation with the engine test results. This questions to some degree the fundamental adherence of the simulated physics. Sometimes the provocative question is posed what the numerical effort is worth if a model validation with hardware is necessary in advance? In order to answer this question, it is necessary to acknowledge, on the one hand, the present state of the research on mixture 
preparation and combustion modelling [1]. On the other hand, the transfer of these methods to the more applied industrial development processes is necessary. It is therefore the goal of this paper to provide an assessment for these two issues based on the current status.

The questions raised above must be discussed together with the present political situation. There is a global trend to promote alternative energy and mobility concepts that challenge the internal combustion engine's perspective and strongly question further research and methodology improvement. In order to achieve a decarbonized mobility by 2050, all processes that emit greenhouse gases and, therefore, have an impact on the global climate will be strongly limited or even abolished. According to the "Green Deal" of the European Union a swift transformation from internal combustion engines to alternative powertrains like battery or fuel cell electric vehicles will be pursued [2]. As a consequence, the internal combustion engine is scarcely mentioned in future funding programs. Anyway, the technical experts and in the meantime the political decision makers are aware that there will be mobility sectors, where a quick replacement of internal combustion engines will be difficult. This is particularly valid for the long-distance air and ship traffic. National strategic papers mention both sectors in connection with decarbonized fuels that are produced with excess electric energy from wind and sun power [3]. At present, large diesel, gas, and dual fuel engines and their further development are obviously accepted beyond 2030. Therefore, this assessment will be mostly related to the combustion process of large engines, i.e., engines that are employed in off-road applications, ship propulsion and stationary power generation. However, most research on the improvement of the modelling capabilities was rather carried out in the field of passenger cars and commercial vehicles and will therefore be mentioned where suitable.

At the very basis of predictive engine modelling there must be an accurate description of the turbulent flow. This is already a source of many shortcomings that are frequently attributed to combustion and emission modelling. Therefore, some general thoughts on turbulent flow modelling will be given followed by spray, combustion, and pollutant formation.

\section{Basic Challenges of Turbulent In-Cylinder Flow}

Turbulent flows are of stochastic nature which makes their numerical treatment challenging. A vivid illustration is the energy cascade with vortex structures (eddies) that are created by the shear flow and break down successively to smaller and smaller eddies that finally dissipate to thermal energy. The spread between the largest and smallest structures strongly grows with the turbulent Reynolds-number [4]. These vortices strongly increase the transport of species, energy and momentum and have a fundamental impact on all in-cylinder processes. Depending on their size they influence mixture preparation, flame propagation, and post-flame chemistry. This demands a suitable temporal and spatial resolution, with moving numerical grid points due to piston and valve motion as an additional numerical challenge. Currently, the most widely used procedure is therefore the Finite Volume method that is implemented in many commercial and open-source CFD codes [5]. To solve the underlying transport equations of continuity, species, momentum, and enthalpy (Navier-Stokes equations: NSE), the direct numerical solution (DNS) would be the most straightforward and predictive methodology neglecting model assumptions. Due to the vast numerical efforts of this methodology the application was strictly limited to fundamental problems. However, there have been first efforts to apply DNS to engine flow and combustion processes during the last years. Schmitt et al. simulated the compression stroke for a simplified combustion chamber geometry to investigate heat fluxes close to the chamber walls $[6,7]$. The authors employed higher-order differencing schemes to account for the stiffness of the NSEs and spatially resolved the flow domain down to the Kolmogorov size, which resulted in cell sizes below $10 \mu \mathrm{m}$ and an overall cell count of up to $1.36 \times 10^{8}$. They quantified their numerical efforts with $353,000 \mathrm{CPUh}$ for the compression stroke only [7]! The investigations of the working group were recently further extended to a $2 \mathrm{D}$ parameter study of the flame propagation from pre- to main chamber where 
they analyzed the production of the vortex pattern by the gas jet in dependency of nozzle parameters [8]. These studies confirmed that DNS will be restricted to fundamental research and model development due to the extensive number-crunching, storage requirements and post-processing efforts to analyze and interpret the vast amount of fundamental flow data. It will remain completely out of scope for industrial applications in the foreseeable future.

From this follows, that the fluctuating turbulent flow must be modelled to some degree which typically involves the introduction of hypotheses or assumptions that may affect the final outcome. The most drastic and currently almost exclusively used approach is the URANS-methodology that solves the NSE in its ensemble-averaged form. This is illustrated in Equation (1) with the velocity component $u_{i}$ as an example:

$$
u_{i}=\widetilde{u}_{i}+u_{i}^{\prime \prime}
$$

$\widetilde{u}_{i}$ denotes the mean velocity or Favre-average, $u_{i}^{\prime \prime}$ the velocity fluctuation. As a consequence, only the mean quantities of mass, momentum, enthalpy, and species are solved, all turbulent fluctuations are represented by more or less sophisticated models [4].

The widely used turbulent-viscosity hypothesis interprets turbulent fluctuations as an increased diffusion of momentum, heat and species. A turbulent viscosity is introduced analogous to the kinematic viscosity of the laminar flow although theoretical and experimental works already demonstrated that this assumption is not applicable under all conditions and counter-gradient turbulent transport may be observed [9]. At present, the 2-equation models lump the whole spectrum of turbulent structures in two parameters that are solved with two additional transport equations. In engine applications, the k- $\varepsilon-$ model is mostly used, and the two mentioned parameters are the turbulent kinetic energy $k$ and the dissipation rate $\varepsilon$, which are combined appropriately to define the flow's local turbulent time and length scale.

From an application standpoint, a benefit of URANS is that it inherently delivers an ensemble-averaged solution, which has been a strong argument for many years when general information of the flow field and the mean combustion cycle was sufficient. Additionally, the interpretation of the turbulence as diffusive transport lowers the Reynoldsnumber and facilitates the numerical treatment. Thus, a decent solution to the inherently stochastic engine process was possible even with limited computing capacities. Despite the assumptions underlying this class of turbulence models, they allowed the widespread application of CFD to the turbulence-governed flows in internal combustion engines in the past decades and the results promoted the knowledge on the role of turbulence in engine performance. On the other hand, considerable simplifications are introduced with the described methodology. The parameters in the transport equations of $k$ and $\varepsilon$ are empirical and based on incompressible, equilibrium turbulent flows [4]. The turbulence is assumed isotropic and all information about the size spectrum and topology of turbulent structures is lost. Isotropy is highly questionable for tumble or swirl flows that are usually imposed on the in-cylinder flow of internal combustion engines to support mixture preparation and flame propagation. The flame front specifically interacts with turbulent vortices of different sizes which requires a more detailed representation of the turbulent structures.

Large Eddy Simulation (LES) on the other hand avoids from a methodological point of view many of the shortcomings of URANS. A filtering operation is applied on the NSE instead of an averaging [4]. In Equation (1) $\tilde{u}_{i}$ now denotes the unfiltered, $u_{i}^{\prime \prime}$ the filtered velocity. All turbulent structures that are of the same size or larger than the numerical grid are resolved directly, while subgrid scale models represent the remaining small structures. LES is therefore a compromise between DNS and URANS. The stochastic character of the turbulent flow is to some degree maintained. From this follows, that cycle-to-cycle variations (CCV) are basically resolved. If LES is executed on industry-typical coarse grids it is frequently referred to as Very Large Eddy Simulation (VLES), if a blending between LES and URANS is part of the numerical solution, it is called Detached Eddy Simulation (DES). A detailed description of the application of LES and its derivatives to internal combustion engines can be found in [10-12]. 
The potential of these advanced methods is evident. The large vortices that are considered decisive for transport and anisotropy are solved directly. The modelling assumptions are far less fundamental than for URANS, hence the resulting flow characteristics are more based on the solution of transport equations and less on models. However, the filtering operation depends on the numerical grid size and LES has therefore strong requirements to mesh resolution, particularly close to walls. The missing turbulent viscosity makes LES more sensitive to numerical diffusion and the differencing scheme order [13]. The modelinherent benefit of an ensemble-averaged URANS solution is lost and a sufficient number of working cycles must be simulated within the LES framework in order to extract the desired statistical information. Generally, model adaption and comparison with test results are not straight forward anymore and the mean engine cycle that is used to correlate URANS simulations with measurements must be substituted by an ensemble of individual cycles.

Several studies were carried out in the past to evaluate the capabilities of URANS and LES regarding the turbulent flow field. In [14,15], swirling flows were simulated with both methods and compared to laser-optical measurements. A good agreement with the measured flow field was found for both methods, but the amount of turbulent kinetic energy was reported as being under-predicted for URANS, and the solution was considered as too diffusive. Zöchbauer proposed in [15] to decrease the turbulent Schmid-number in order to adjust the turbulent mixing for the URANS approach. Nemati et al. applied URANS and LES on the scavenging process of a large 2-stroke diesel engine and compared their results with PIV data. Although they found a good agreement with the measurements for both solutions, too, they stated a better prediction of the tangential velocity for LES [16]. Very similar results were found for an uniflow-scavenged cylinder in [17] and for an optical engine in [18]. Liu compared an axisymmetric piston-cylinder assembly with and without swirl flow and came to the conclusion that neither URANS nor LES provided a completely satisfying representation of the measurements with advantages for the more expensive LES [19].

Optical engines were established with the goal to provide measurement data for an advanced evaluation of turbulence models [20,21]. These research activities provided a considerable database of flow and flame data during the last years that was used by the community to validate the CFD codes with respect to turbulent flow, mixture preparation and combustion [22,23]. A hybrid formulation of URANS, DES and LES was investigated in [24] and compared to PIV-like experimental data from the TCC-III engine and full-LES results. In [25] a SI engine with direct injection was investigated with the aim to evaluate the impact of CCV on the flow field and mixture preparation at the spark plug. The authors concluded that LES is a valid method to develop engines with respect to flow and mixture preparation.

The general conclusion from the literature, that URANS delivers comparable results for the flow field but differs from the more detailed LES with respect to turbulent kinetic energy shall be illustrated in the two following figures. In Figure 1 the calculated flow field of a large bore dual fuel engine with a cylinder displacement of approximately $5 \mathrm{~L}$ is shown during compression stroke at an engine speed of 1800 RPM. The calculations were carried out with LES as a reference using the Coherent Structure subgrid model and URANS with

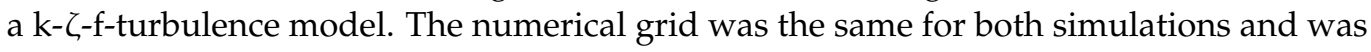
considered sufficiently fine for LES. It had a bulk cell size of $0.5 \mathrm{~mm}$ and a cell number of $1.2 \times 10^{7}$ was reached at BDC. The amount of turbulent kinetic energy contributed by the SGS was well below $10 \%$ and fulfilled the criterion suggested by Pope [4]. Overall, 25 LES-cycles were run consecutively on approximately 300 cores of the Vienna Scientific Cluster (VSC), which took an overall simulation time of more than two months. 

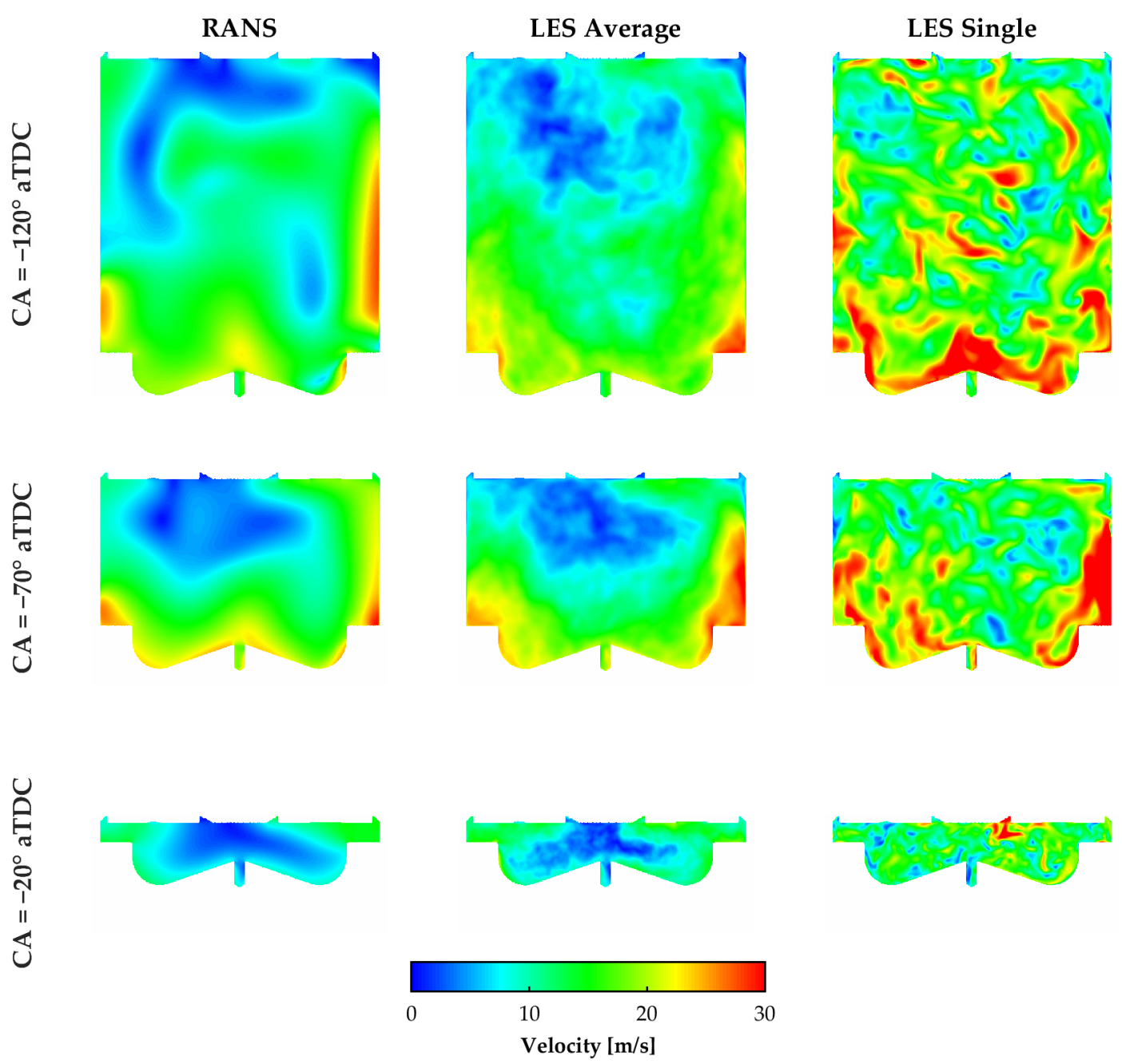

Figure 1. Flow field of a large bore dual fuel engine during compression stroke at 3 different crank angles simulated with Large Eddy Simulation (LES) (right) and URANS (left); averaged LES results from 25 cycles are shown in the (middle column).

The ensemble-averaged URANS solution is illustrated for 3 different crank angles between inlet valve closing and start-of-injection in the left column. In the right column, the LES result is shown for an individual cycle that delivered a burn rate that was close to the engine's measured average burn rate. The differences are apparent and demonstrate the impact of the ensemble averaging. While URANS represents only the global flow patterns in the combustion chamber, the instantaneous turbulent vortices are visible for the LES simulation. This is important to note when discussing mixture preparation and combustion. When averaging the 25 simulated LES cycles, the flow field is very close to the URANS solution, see middle column of Figure 1. Particularly the region of low velocity in the center of the combustion chamber due to the swirl flow pattern is well represented.

In Figure 2a contour plots of the turbulent kinetic energy are compared for the same 3 crank angles. The turbulent kinetic energy was derived from the velocity fields of the LES cycles according to the methodologies discussed in [26,27]. In contrast to the flow field the highest values of the turbulence can be noticed in the center of the combustion chamber due to the breakdown of the flow structures. From a qualitative point of view a resemblance between URANS and LES can still be observed. 

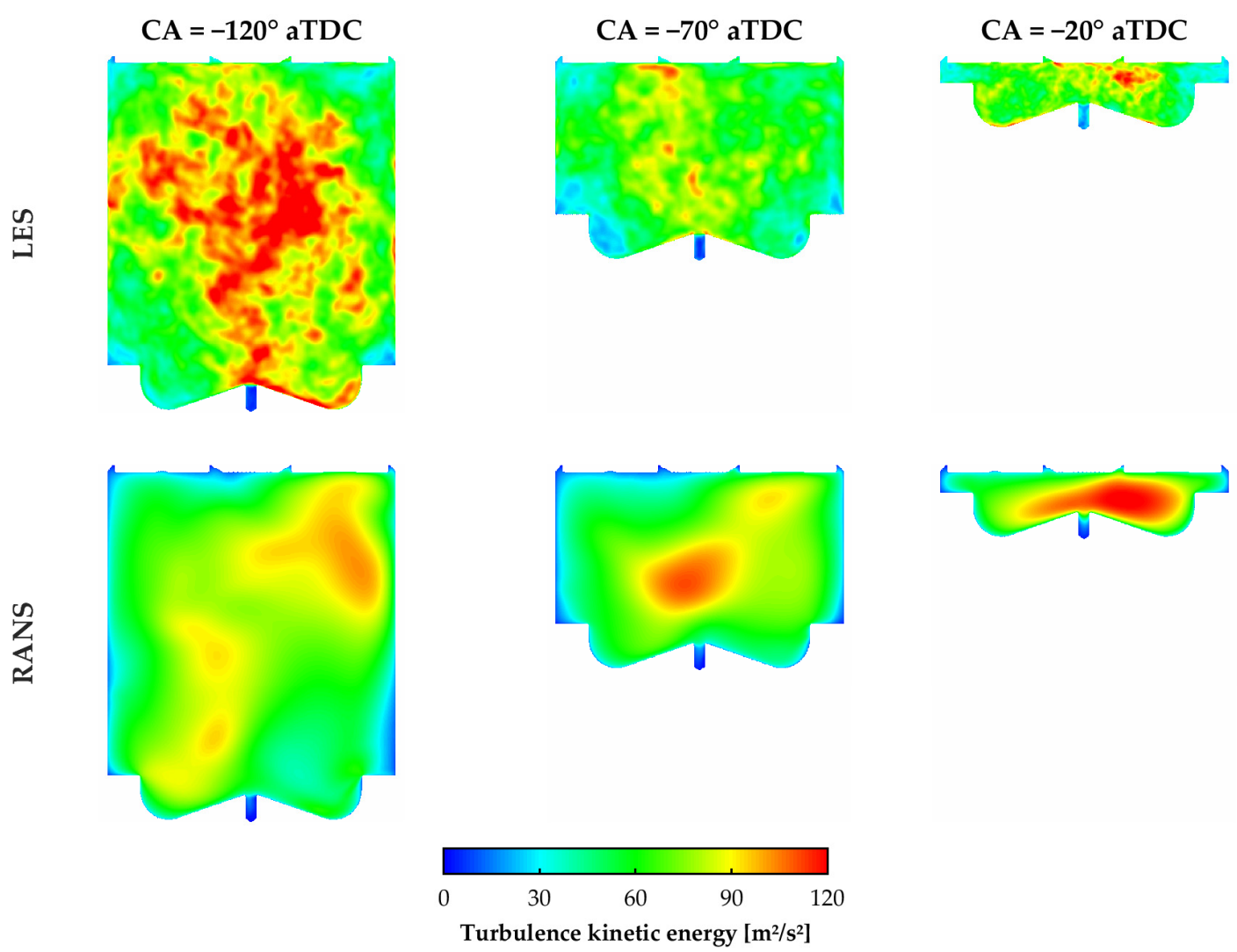

(a)

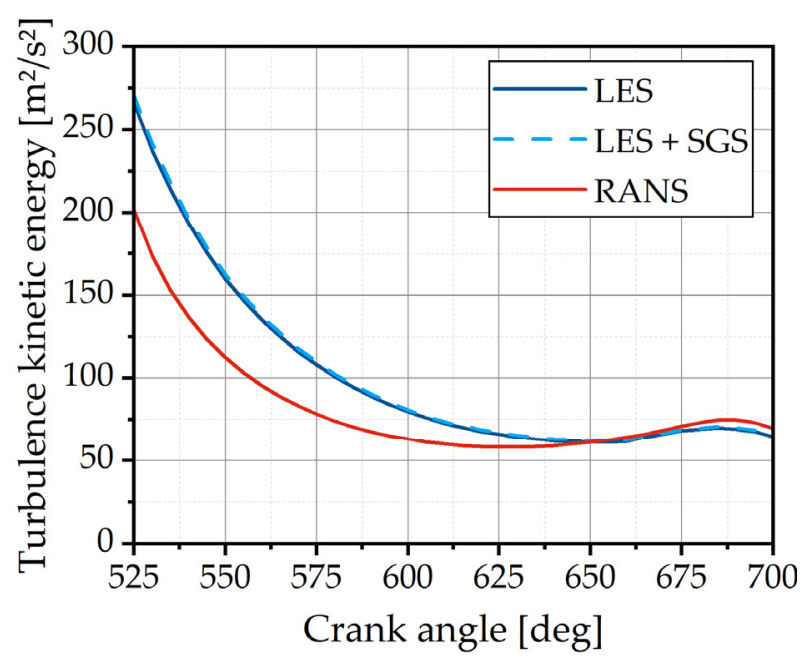

(b)

Figure 2. (a) Turbulent kinetic energy in the combustion chamber of a large bore dual fuel engine during compression stroke for 3 different crank angles simulated with LES (upper row), RANS (lower row); (b) average turbulent kinetic energy over degree crank angle for RANS and LES (with and without SGS).

However, especially after inlet valve closing, the absolute amount of turbulent kinetic energy is higher for the LES solution which confirms the observations of other authors mentioned above. Additionally, the regions in the combustion chamber with high turbulent kinetic energy are getting steadily larger for URANS compared to LES, which supports the conclusion of enhanced diffusivity. Figure $2 b$ illustrates the average turbulent kinetic 
energy over degree crank angle for both turbulence models and clearly depicts the higher turbulence level of LES over a wide range of the compression stroke. The results from LES are depicted with and without the contribution from the SGS model. The small difference between both graphs underlines the high amount of resolved turbulence.

It follows that LES, as already reported in [12], generally shows additional potential to provide more accurate results of the turbulent flow field. This is important for downstream processes like mixture preparation, combustion, and pollutant formation. The question is if the substantial increase of the numerical costs will be accepted, or, alternatively, if it will be possible to cut down computational runtime.

\section{Boundary Conditions}

An essential prerequisite of an accurate CFD simulation is the availability of clearly defined boundary conditions. However, the boundary conditions of internal combustion engines are complex and not known in detail. This aspect is often excluded from the discussion.

\subsection{Wall Flow and Heat Transfer}

The resolution of the viscous and turbulent shear layer at the combustion chamber walls is still a considerable challenge with respect to the various flow patterns and temperatures that occur during gas exchange, compression, and expansion stroke. The most common modelling approach is the logarithmic law of the wall that was derived from an incompressible, steady-state wall flow in local equilibrium [4]. It is usually applied in conjunction with URANS, VLES and DES simulations. Engine specific modifications of the turbulence model and the analytical formulations were added e.g., by Angelberger and Keum, who took variable fluid properties and densities in the wall layer into account, and the Modena working group that proposed a modified law of the wall formulation in order to overcome the different heat flux predictions for pancake shaped research combustion chambers and roof top shaped geometries of SI engines [28-30]. Šarić et al. propose an analytical wall function instead of the log-wall model in conjunction with a k- $\zeta$-f-turbulence model and conclude from a wide range of benchmarks less mesh sensitivity and better quality [31]. However, a prerequisite for an accurate model application is that the dimensionless distance $y+$ of the first numerical grid point is in a suitable range for the whole working cycle. Though it is an issue for continuing development [32], this criterion is usually not fulfilled as long as no adaptive meshing strategy is involved.

Alternatively, the low-Reynolds approach with a numerical resolution of the wall layer is applied, especially in combination with LES. The assumption of normalized velocity and temperature profiles close to the wall as they are inherent to wall layer models can thus be avoided, but a sufficient numerical resolution of the viscous and turbulent wall layers is necessary. Particularly for highly turbulent flows, the wall layers are very thin. In combination with the fact that a LES simulation requires a fine mesh perpendicular and parallel to the wall, an excessive mesh size results. At ETH Zürich an engine process was simulated using DNS with the goal to gain insight into the transition from the turbulent to the viscous shear layer. Detailed results on near-wall flow structures are expected that will help to improve future URANS and LES heat transfer models [33].

Besides the shear flow in the wall layer, the surface temperatures of piston, liner, and cylinder head including the valve disks are essential. It must be assumed that these temperatures are non-uniform in space and time and interact with the turbulent in-cylinder flow and the flame front. Wu et al. pointed out the impact of a more elaborate conjugate heat transfer model on the flow field and heat transfer in a pancake shape research engine [34]. Though efforts were made in the past to include simplified 1D-models to solve for the wall temperatures or to map transient wall temperatures from FE analyses on the CFDgrid [35,36], constant surface temperatures are still state-of-the-art and an uncertainty of the numerical solution. 
Additionally, the surface finish is usually not considered in the definition of the cylinder walls and may differ throughout an engine's lifetime due to wear and contamination. The cylinder liner and the piston surface are wetted with fuel and lube oil and an impact on flame quenching and heat transfer cannot be excluded.

When accepting that hydrogen combustion with high laminar velocities, high Pécletnumbers and a rather small quenching distance of the flame at the combustion chamber walls will play a prominent role for future engine combustion processes, the predictive modelling of the wall heat transfer will remain an important research issue in the future.

\subsection{Gas Exchange and Cylinder Pressure}

Fluid mechanic properties like pressure, temperature, and mass flow must be assigned to the in- and outlet of the CFD domain. The necessary time-dependent data is taken either from low-pressure indication measurements from a test bed or gas exchange simulation with a suiTable 1D-code. If the inlet boundary is defined sufficiently far upstream of the inlet valve, the impact of the, particularly for LES unknown and therefore assumed, turbulence intensity at the inlet on the flow field after inlet-valve-closing can be minimized.

It was already discussed that the consecutive simulation of engine cycles with LES is tremendously time consuming. Therefore, investigations were carried out to perform multiple parallel simulations by effectively perturbing the simulation parameters such as the initial and boundary conditions in order to compute a sufficient number of individual cycles in an acceptable time [37]. The authors related these perturbations to turbulence intensity in the combustion chamber. In $[38,39]$ a concurrently saved flow field is perturbed with random minuscule velocity fields to generate a number of slightly different flow-fields for following simulations. The CCV of a dual fuel engine were simulated in [40] by running multiple parallel cycles with perturbed operating parameters and boundary conditions. Single- and multi-parameter perturbations were investigated. In [39,40], both authors claim that high-performance computing power was available and enabled a strong parallelization. Especially in combination with further growing computing power, this approach seems very promising and a substantial parallelization of LES cycles may be a game-changer in favor of this method. However, a sufficient database is missing, and further research will be beneficial in order to promote the confidence in the applicability of such a method to further engine configurations.

Further, the ideal gas assumption is not valid at high pressures and real gas options should be considered. Yue et al. modelled the cylinder charge of a conventional diesel combustion engine and in a reactivity-controlled compression ignition engine with a PengRobinson formulation and reported a good agreement to test results and a discrepancy of the predicted emissions and reaction kinetics to the results with ideal gas assumption with increasing load [41]. The authors concluded that the inclusion of real gas effects is important.

It is uncertain for large bore engines if the impact of radiation on heat transfer and fluid thermodynamics can be considered negligible. In [42] a share of 10 to $20 \%$ of the overall heat transfer mainly due to gas emissivity was calculated with CFD simulation for a diesel engine. Therefore, basic fluid properties like the mixture temperature and pressure are obviously subject to uncertainties.

Elasticities in the engine structure (cylinder head bolts, crank train) may noticeably change the combustion chamber volume and compression ratio compared to the ideal CAD geometry for highly boosted gas and diesel engines with peak pressures beyond 25 MPa. This is discussed in [43] for an optical engine and extended to full-metal engines at higher boost and peak pressures. which is of particular relevance for large engines [44]. The blow-by losses and their impact on the engine process strongly depend on the piston ring tension and are generally unknown.

While these simplifications were frequently acceptable for the simulation of the mean engine cycle with URANS there might be a need to re-evaluate these shortcomings when 
the whole cycle spectrum is to be simulated with LES in order to predict the kinetically controlled processes of pollutant formation and knocking combustion.

\subsection{Injection and Spark Ignition}

Further boundary conditions are fuel injection and spark ignition. Both supply of diesel and spark energy are prone to variations themselves that cannot be attributed exclusively to the flow field. The more local the mixture ignition, as is the case for spark ignition and dual fuel engines, the higher is the impact of the local variations of the turbulent flow field on the following combustion process. Particularly LES simulations must include these variations if it is the aim to predict CCV. It is important to be aware that LES itself only captures the stochastic nature of the turbulent flow itself. Consequently, it was reported in the past that LES simulations did not cover the whole cycle spectrum observed at the engine test bed $[45,46]$. Kinetic processes are frequently strongly related to the fastest (knocking combustion) and slowest cycles (HC-emissions). Only if these cycles are captured accurately by LES simulation, the correct conditions of the cylinder charge are provided to solve for the reaction kinetics. Investigations by Goryntsev et al. already depicted the potential of stochastic perturbations imposed on the spray of a GDI engine in combination with a LES turbulence model [47]. Similar approaches may be applicable to spark modelling. However, this is still content of current research activities and further experience must be gained before a successful application to different engine types is possible.

\section{Mixture Preparation and Ignition}

Spray formation is complex and strongly depends on details of the nozzle geometry like the fillet between cavity and bores, the shape of the bores, and surface roughness. Turbulence and cavitation bubbles within the liquid core are generally unknown boundary conditions when the fuel enters the combustion chamber. Although numerous models are available that represent the phenomenology of spray atomization and droplet breakup [48], parameter adaption for a given setup is still necessary [13]. The vast number of single droplets in a typical engine spray requires a statistical approach. Therefore, the droplet distribution is characterized by the spray equation, which is numerically solved on discrete trajectories by a sufficient number of stochastic parcels in a Lagrangian manner. Further spray models like droplet coalescence and turbulent dispersion are nowadays implemented in every commercial CFD code. A more complete summary of current spray models is given in [48-50].

Otto et al. discussed the model-intrinsic shortcomings in detail that arise from an insufficient grid resolution close to the injector nozzle, the influence of grid cell orientation relative to droplet trajectories, the lack of statistical convergence and an unphysical turbulence formation in the spray [13]. According to Haworth liquid fuel-spray modelling is a "particularly weak link" [51]. Though remedies were proposed that introduced adaptions to the turbulence model in combination with a hybrid Euler-Lagrange approach [52] or fluid diffuse-interface model [53] to overcome mesh dependencies close to the nozzle, a predictive simulation without injector specific model calibration has not been reported so far. Comprehensive modelling approaches that included the nozzle flow in the simulation moved the boundary conditions to a more favorable position inside the cavity, but the numerical efforts seem too high for an industrial application, particularly when considering that details of the nozzle geometry are frequently unknown [54,55]. Further, typical grid sizes of the combustion chamber and injector nozzle differ by orders of magnitude, posing severe constraints for their coupling in a unique simulation.

The modelling approaches for spark ignition suffer similar problems as injection models. Neither the spatial nor the temporal resolution is given on a typical CFD grid to describe the physics of a spark ignition process accurately. Phenomenological models were introduced to define a flame kernel with reasonable initial conditions for the following turbulent combustion. An interaction of the flow field during arc and discharge 
was described with Lagrangian particles (AKTIM). A brief review of current modelling approaches can be found in [56]. Spark plugs of large gas engines have a smaller spark gap and larger electrode surfaces compared to gasoline engines due to the lean mixture and the high gas pressures during ignition. Therefore, modifications of existing models with respect to heat transfer and turbulent diffusion are necessary. Although a methodology was demonstrated in a URANS framework in $[56,57]$ and a comprehensive workflow for a DISI gasoline engine based on LES and including an AKTIM spark model is described in [46], a specific large engine model for LES is still missing.

There is ongoing research on spray penetration, mixture preparation, ignition lift-off length and robustness. Numerous models were extended and validated with the help of detailed geometry and spray data from reference injectors (e.g., the injectors of the Engine Combustion Network). The modelling of the mixture fraction and the interaction of turbulence and chemistry was already investigated on different complexity levels using transported probability functions (TPDFs) $[58,59]$ and lower-order manifolds, like conditional manifold closure (CMC) [60-63], flamelet generated manifolds (FGM) [64-66], or even assuming the computational cells being well-stirred reactors [67]. LES was frequently applied to investigate in detail different sub-processes of the diesel injection, like the impact of turbulent dispersion [68] and turbulent structures [69] on lift-off length and cone angle, the mixing fraction close to chamber walls [70], or the primary-breakup [71].

Additional complexity to injection and ignition is added by multiple injection and variations of the background gas. Both split injection and dual fuel introduce various mixing and combustion regimes that must be treated simultaneously. Bolla therefore simulated multiple-injection cases using transported PDFs (TPDFs), compared the CFD results with measurements of the spray A injector and reported a good agreement [59]. Hasse successfully applied an extended flamelet approach to a diesel split injection [72].

Analytical conclusions from numerous experimental observations on typical diesel sprays suggested that the spray penetration is mainly driven by the initial spray momentum and the air-entrainment by the cone angle [73], i.e., the diesel spray behaves similar to a gas jet and equilibrium between gaseous and liquid phase can be assumed. Obviously, modelling results with respect to spray penetration and mixture formation are not too sensitive as long as a correct momentum and spray angle are provided. Therefore, solutions were proposed that rather aimed on a high robustness and industrial applicability. In [67] the primary break-up model was extended in order to analyze the impact of cavitation and turbulence on droplet size, penetration and cone angle for a diesel spray. In [74] a simplified approach based on phase equilibrium was proposed, validated with experiments and grid-independency and minimal necessary tuning was claimed. Wang combined an extended primary break-up model with an unsteady gas jet approach to minimize mesh and time step dependencies of the solution [75].

The simulation of the mixture ignition requires, besides the accurate representation of the species concentrations in the gas phase, suitable kinetic mechanisms to model reaction rates and heat release. This will only be mentioned briefly because the development and reduction of chemical mechanisms usually require specific experimental devices and numerical tools. The kinetic mechanisms are frequently coupled to the CFD codes via standardized interfaces. In the past, numerous mechanisms for diesel, fuel gases with different methane numbers and surrogates were developed using rapid compression machines, shock tubes and reactor models. They were either directly implemented or tabulated for their efficient use in the CFD framework. Successful development and reduction of detailed dodecane-mechanisms with the aim to predict auto-ignition were presented in [76-78]. Reduced chemical mechanisms for dual fuel combustion, which mostly used n-heptane as diesel and methane as natural gas surrogates, were developed and applied to engine processes in [79-81].

While the research on diesel sprays mainly aimed to describe chemistry and mixingstate, Chung considered supercritical fluid properties to identify flow sensitivities due to geometry variation in conjunction with the impact of low-temperature oxidation [82]. 
Perini reported an impact on spray temperatures and saturation properties when using real-gas options [83]. Though it is not directly related to large engines, it shall be briefly mentioned that in the field of gasoline fuels, the impact of physical as well as chemical fuel properties are more and more investigated. Zöbinger suggested a surrogate fuel consisting of 11 hydrocarbons in order to reproduce the fuel's distillation curve with the aim to predict film formation in the combustion chamber of a DISI engine more accurately [84]. Del Pecchia extended existing physical and chemical models to a comprehensive approach that predicted flame propagation and auto-ignition correctly [85]. A "mixed-mode" combustion was investigated for E30 in [86] with a surrogate that was adapted to RON- and MONnumber. The authors reported a correct prediction of pure deflagration and mixed-mode combustion that additionally showed auto-ignition.

Frühhaber et al. applied the WAVE-atomization model to a dual fuel injector that was operated in the ballistic range and took the impact of needle-opening and -closing into account. Turbulence was modelled with LES, chemistry with a reduced n-heptane/methane/ propane-mechanism assuming well-stirred conditions in the computational cells [81]. Comparisons with penetration lengths that were measured in a constant-volume chamber showed a good agreement after adjusting initial velocity, spray angle and droplet atomization (break-up time, child-parcels) [87]. Figure 3 depicts a comparison of the measured and simulated spray ignition through the $\mathrm{OH}$-radical at different timings after start-of-injection for the discussed injector [87]. The model successfully reproduced the ignition close to the nozzle in the spray's boundary zones where air-entrainment and mixture preparation provided favorable conditions for ignition. After the end of injection, the flame moves to the spray tip and consumed the fuel in the spray center. Despite the simple approach with respect to turbulence/chemistry-interaction, a good correlation between simulation and measurements could be observed with respect to ignition delay as well as ignition location. This further supports the statement that with a well-adjusted injection model and kinetic mechanism reasonable results can be achieved.

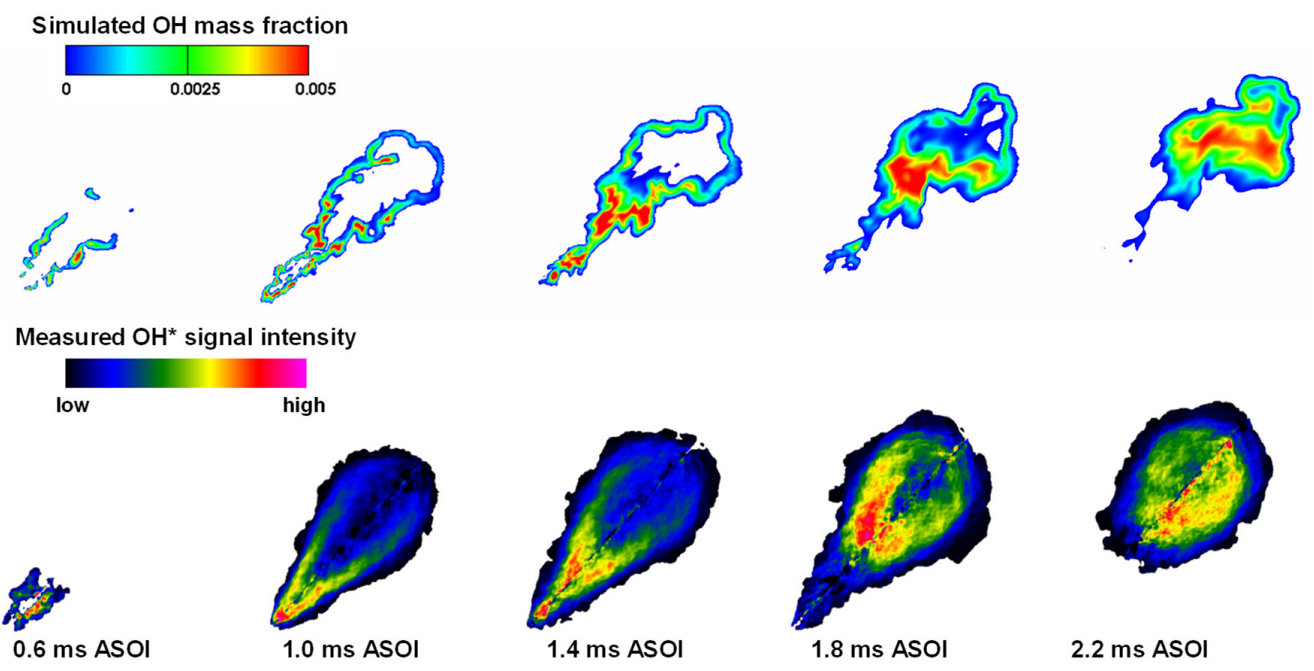

Figure 3. Simulated and measured $\mathrm{OH}$-species during the ignition of a diesel spray.

In the future, the chemical and physical characterization of fuels will become one of the key challenges of CFD simulation. It must be expected that engine research will be shifted significantly to alternative fuels without $\mathrm{CO}_{2}$-footprint [88]. There is intense discussion about Power-to-X fuels that use excess energy from sustainable but volatile resources like sun and wind power and therefore act as chemical energy storage.

With respect to gaseous fuels, hydrogen from electrolysis is considered the most promising power source in the future. In addition to supplying fuel cells, hydrogen can be a potential source of energy for large gas engines. As an example for these emerging technologies, the activities at the Large Engines Competence Center in Graz, Austria, shall be mentioned, where the on-board preparation of hydrogen from water and carbon dioxide 
using liquid methanol as an intermediate storage is currently demonstrated [89]. Therefore, specific properties of hydrogen combustion must be further investigated, specifically the simulation of the penetration and mixing of the under-expanded fuel gas jet, the characterization of laminar and turbulent flame speed, flame quenching distance and wall heat losses as well as auto-ignition. First simulation results are shown in [90].

From hydrogen and carbon dioxide, liquid synfuels can be produced with the FischerTropsch process. Though this path is disadvantageous from an efficiency point of view, it can be argued once there is a sufficient amount of excess energy available to store or consume. For large engines oxymethylene ethers (OME) might be a future substitute for marine diesel or even heavy fuel oil [91,92]. A wide range of physical and chemical properties is realizable depending on the number of carbon atoms in the molecule and an application of these fuels could be ramped with admixtures to marine diesel as a starting point. From the perspective of the CFD simulation that means above all the development and availability of suitable chemical mechanisms.

It can be concluded that LES and URANS have been successfully applied to the injection of sprays and the ignition process. However, both approaches required the coupling with a validated spray or spark ignition model and an improvement with respect to prediction capability cannot easily be derived for LES from this point of view. Meshand timestep-sensitivities and an atomization process that cannot be properly resolved with present numerical discretization will remain prone to expertise and validation.

\section{Combustion}

The combustion process in engines is strongly affected by the turbulent flow field that promotes the mixing of fuel and oxidizer and the flame propagation. It is useful to distinguish between premixed and non-premixed combustion, although such distinction is less and less valid for modern combustion strategies. Diesel combustion is generally considered non-premixed, i.e., fuel and oxidizer mix and burn simultaneously. Gas engines with fuel admixture far upstream the inlet valves are almost perfectly premixed, and a turbulent flame front propagates through the homogeneous cylinder charge consuming the fuel. Flame characteristics can be expressed with the turbulent and chemical time scales. For many combustion processes, like the diesel diffusion combustion or the premixed combustion of a SI engine, the chemical timescales $\tau_{\text {chem }}$ are much smaller than the turbulent time scales $\tau_{L}$, i.e., the Damköhler-number $D a$

$$
D a=\frac{\tau_{L}}{\tau_{\text {chem }}}
$$

is large. In this case, the reaction zones are thin and the turbulent flame, though wrinkled by the turbulence, still behaves on a microscale like an ensemble of laminar flame sheets (flamelets) [93] which allows, from a modelling point of view, the separate treatment of the chemical and the turbulent aspects of the combustion process. Typical flame regimes of large internal combustion engines are illustrated in Figure 4. The interaction of turbulence and chemistry is complex and strongly depends on the size of the turbulent structures. Large eddies may contribute to a wrinkling of the flame and therefore to an enlargement of the reactive surface, small eddies of the size of the flame thickness or reaction zone cause species and heat transport on a microscale. This may lead to a degradation of the gradients in the reaction zone and result in a thickened and strained flame front [93]. These effects on the smallest scales are expressed by the Karlovitz-number Ka that relates the Kolmogorov time scale $\tau_{K}$ to the time scales of the laminar flame $\tau_{L}$ [93], see Figure 5.

$$
K a=\frac{\tau_{L}}{\tau_{K}}=\left(\frac{\delta_{L}}{\eta}\right)^{2}
$$




\section{Turb. premixed flame}

(Da $\gg 1)$

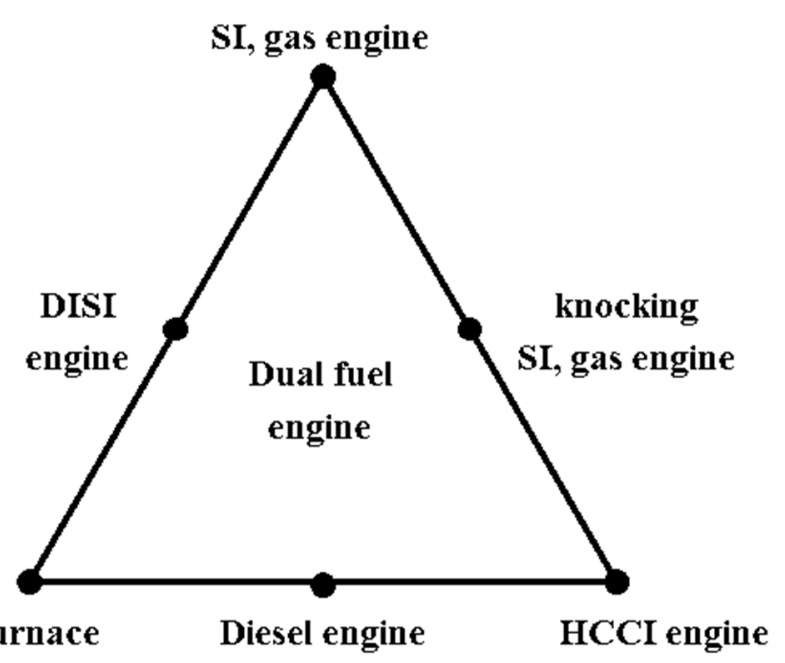

Turb. non-premixed flame (Da $\gg$ 1)

Figure 4. Flame types in combustion engines (based on [49]).

UNBURNED

BURNED

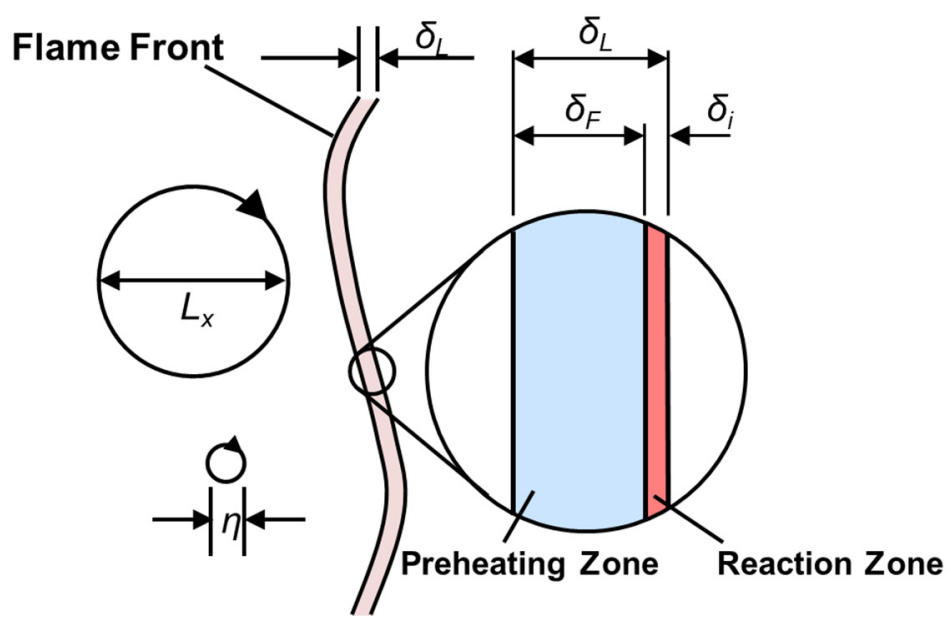

Figure 5. Length scales in turbulent combustion acc. to Peters.

Obviously, the flame characteristics are widely different, reaching from laminar flames to wrinkled or even corrugated flames with fast chemistry that are strongly affected by the turbulent structures. If chemistry is slow compared to the turbulent time scales, the reacting mixture may be assumed well-stirred. Flames in internal combustion engines cover the whole range of flame characteristics, see Figure 4. Diesel combustion usually starts with the auto-ignition of premixed fuel and transitions into diffusion combustion. It is therefore located in the center of the combustion triangle's base line. The combustion process in a gas engine may start with a propagating flame front that causes a self-ignition in the unburned mixture if the knock limit is reached.

In the framework of a RANS approach the species conversion (combustion) is treated mathematically as the Favre-averaged reaction rate in the species transport equations. Numerous models were proposed for this term that reach from rather simple time scale to sophisticated PDF and multi-zone models, which already reflects the wide variety of 
combustion characteristics that must be covered. A summary and review of available combustion models is given in [49,94] and in the combustions models table of [51].

LES simulation with a more detailed representation of turbulent scales can be considered as a solution for shortcomings of turbulent mixing and wrinkling of the flame as long as the large structures are involved. However, either using RANS or LES, combustion occurs at the unresolved scales of the computations which makes the general potentials of LES according to [51] "less compelling". The basic tools and formalisms of turbulent combustion modelling are somehow the same for both techniques. Most of the RANS combustion models can therefore be modified and adapted to LES modelling [51].

\subsection{Flame Propagation}

As mentioned above, the flamelet assumption is justified in many cases of engine combustion which allows a separate modelling of turbulence and chemistry. Research work carried out by Dinkelacker and, more recently, Hasse suggested that flamelet-resembling structures can be observed even at high Ka-numbers which theoretically justifies the extension of the flamelet approach to a wide variety of combustion processes $[95,96]$. For nonpremixed combustion, species concentrations from chemistry simulations of counter flow flames were frequently tabulated and related to the CFD solution of the turbulent flow field with a PDF distributed mixture fraction. For premixed combustion a reaction progress variable (e.g., G-variable) and/or a flame surface density (ECFM) is transported, and the chemistry is treated with the mixture's laminar flame speed. Multi-zone combustion models like ECFM-3Z were developed that allow the description of the mixing of the reactants and the combustion as successive processes in specific zones [97]. They are considered applicable to premixed and non-premixed combustion regimes and are in the meantime implemented in most commercial CFD-codes.

Limitations of the present combustion models were intensively discussed in the literature $[13,51]$. The simplified treatment of turbulence within the URANS framework reduces the interaction of the turbulent eddies with the reaction zone to a simple definition of turbulent time scales $\tau_{T} \sim k / \varepsilon$ and length scales $l_{T} \sim k^{1.5} / \varepsilon$. This is the case for the modelling of the important scalar dissipation rate in the flamelet models as well as for the turbulent mixing time and the surface production term in the ECFM model. Premixed combustion models additionally suffer of unphysical turbulence production due to a steep velocity gradient from unburned to burned mixture that cannot be properly spatially resolved and must be suppressed or neglected [13]. Flame regimes with the turbulent and chemical time scales in the same range are not accurately covered by these approaches and a joint solution of turbulence and chemistry is necessary. Enhanced flamelet models that describe the turbulence/chemistry interaction in more detail (RIF, FGM, CMC) were therefore introduced and research work is still going on [64,98-101]. Generally, the numerical effort is considerably increased and the application in an industrial context is still in the process of being clarified. On the other hand, the sophisticated modelling approaches allow a deep understanding of the flame structure and emission formation.

In numerous papers a successful application of different modelling approaches to diesel engines was reported in the past [51], specifically in [60,101] for large engines. Haworth concluded that with careful tuning, a useful representation of the underlying physics can be satisfactorily captured by different modelling concepts. On the other hand, it has proven more challenging to predict even global characteristics (e.g., in-cylinder pressure traces) for different engines over a wide range of operating conditions (engine load and speed) using one model [51].

For premixed lean burn gas engines, the combustion models strongly rely on laminar and turbulent flame speed [102]. Though research has been done during the last years to provide data on the high-temperature chemistry and the interaction with turbulence $[102,103]$, an extension of this database to high pressures beyond $10 \mathrm{MPa}$ as well as very lean mixtures and low laminar flame speeds is still needed [104]. Simulations of an un-scavenged prechamber with the G-equation model revealed that the turbulence/flame-interaction differed 
significantly from the conditions in the main chamber and an extended formulation of the turbulent flame speed was necessary [105]. In [106] the necessity to individually adapt a multi-species PDF combustion model for the pre- and the main chamber was reported in order to find a good correlation with the measured burn rates.

The probably most complex combustion process nowadays with respect to chemistry and turbulent mixing is the dual fuel combustion, especially with a high amount of diesel fuel. All mentioned flame regimes may occur, starting with diesel-like combustion that transitions to a lean burn premixed combustion and may, if the knock-limit is reached, result in an auto-ignition of the homogeneous, unburned mixture. In [107] the authors used a combination of coherent flame and surface wrinkling model and declared that in spite of capturing some physical trends, further improvements of the mixing controlled combustion are still needed. Research work was carried out with a special focus on the extended chemistry involved due to the two fuels in [108-110]. Eder et al. showed results with an ECFM-3Z model and empiric correlations for ignition delay and laminar flame speed [111] that reasonably correlated with test data. In [65] a FGM model was successfully applied to a large bore dual fuel engine. In [66] it is reported that all phases of dual fuel combustion could be successfully captured in a rapid compression machine with a FGM combustion model that was based on calculations of flamelets and mixture fraction. According to the authors, there are further investigations in real internal combustion engines planned to confirm the general applicability.

Figure 6 shows results of a combustion simulation with LES for a large dual fuel engine using a WAVE atomization and a LES-CFM combustion model. A reduced chemical mechanism was specifically developed in order to model the ignition of the diesel/natural gas mixture [81]. The penetration of the spray, the cone angle and the fuel ignition were validated with experiments in a spray chamber, see Figure 3. The simulations were carried out for different diesel substitution and exhaust gas recirculation rates, reaching from small pilot injections of $1 \%$ fuel energy content up to considerable diesel energy rates of $20 \%$. Every operating point was simulated with 25 consecutive cycles in order to provide sufficiently reliable statistical information of the cycle-to-cycle variations. In Figure 6a a snapshot of the spray and the combustion process for a diesel amount of $5 \%$ fuel energy at $10^{\circ}$ after TDC is given.

Figure $6 \mathrm{~b}$ depicts the simulated coefficient of variation $\left(\mathrm{COV}_{\text {pmax }}\right)$ of the peak pressure, which is a measure for the cycle-to-cycle variations, for 3 different diesel substitution and EGR rates in comparison to experiments at the engine test bed. The results show that the cycle-to-cycle variations decrease with a larger amount of diesel fuel. This tendency can be explained by the fact that the spray volume promotes favorable conditions for fuel ignition at numerous locations in the combustion chamber which makes flame development less sensitive to the local fluid properties. For small pilot injections (1\% fuel energy) the local mixture in the vicinity of the injector has a strong impact on ignition and the development of the flame kernels. Therefore, the cyclic variations are highest at this operating point. The LES simulation plainly represents this tendency of the dual fuel combustion which is a basic requirement for emission simulations.

Following the discussion so far, LES is undoubtedly a step towards predictive combustion modelling compared to URANS. As reported, the turbulent flow field's representation is more accurate, and many aspects of the species transport and the interaction with the reactive zones are directly solved instead of modelled. In [112] a comparison of both approaches was carried out for a diesel combustion process and the superiority of the LES approach was confirmed. However, turbulent structures of or below the grid size have an impact on the temperature and species gradients in the reaction zone and modelling approaches must be introduced for LES as well. On the other hand, even for combustion processes with highest complexity like dual fuel combustion, a successful application of URANS in combination with validated mixing and combustion models was demonstrated. It will therefore depend on the aim of the simulation what method will be chosen in the future. Suppose the impact of specific parameters on the heat release are to be investigated, 
like spray properties, or the design of the connecting bores between pre- and main chamber. In that case, URANS may remain the most efficient approach. On the other hand, LES will be necessary whenever the solution of the ensemble-averaged cycle is not sufficient (irregular combustion, emissions) or when the combustion process is insufficiently known and the choice of the combustion model is not straight-forward.

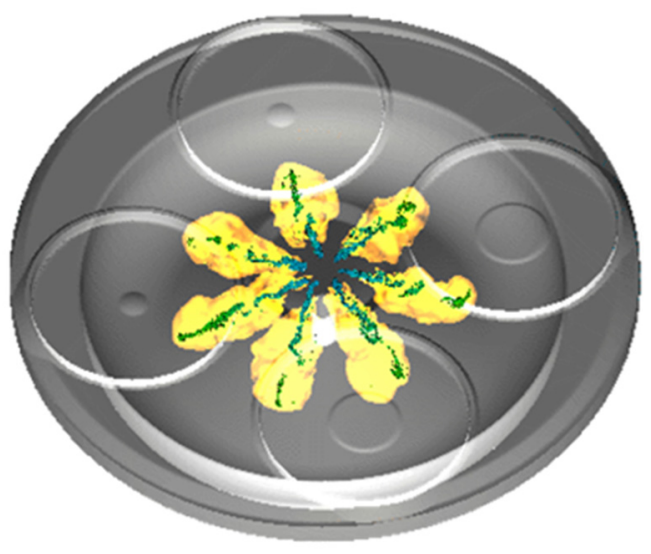

(a)

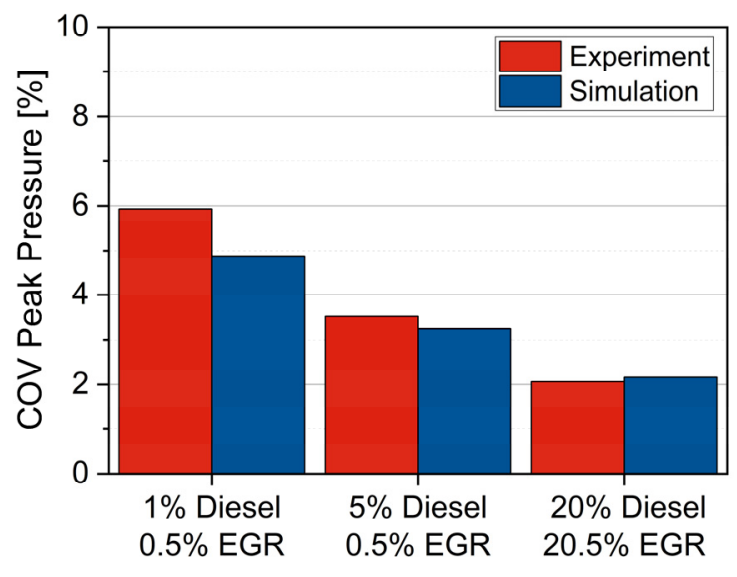

(b)

Figure 6. (a) Snapshot of the duel fuel combustion at $10^{\circ}$ after TDC showing the spray parcels and an iso-surface of the progress variable; (b) Comparison between simulated and measured cycle-to-cycle variations for a large dual fuel engine with different diesel substitution rates.

\subsection{Irregular Combustion}

Knocking combustion is closely related to cycle-to-cycle variations and it is accepted that only a limited prediction is possible using the ensemble-averaged cycle, which is provided by URANS. This has been a strong argument for the promotion of LES in the last years. However, as already mentioned, the impact of perturbations introduced by the injection or ignition systems on the cycle-to-cycle variations is frequently not known and therefore neglected.

Additionally, only a limited number of numerical cycles can be simulated. If we consider as an example a premixed combustion process at the knock threshold and assume that the probability that a cycle with knocking combustion occurs is $p$, it follows that $n \geq \ln (1-p) / \ln (1-B)$ cycles must be simulated to capture a knock event with a Bernoulli certainty of $B$, i.e., with $p=5 \% 14$ cycles for $B=50 \%$ and even 45 cycles for $B=90 \%$. Currently, the simulation time for a complete engine cycle with LES on a powerful HPC cluster is between two and three days. From this follows that the simulation time of 
one engine operating point is in the range of two to three months if these cycles are run consecutively. In most studies 15 to 20 simulated cycles were reported, which suggests that the whole cycle spectrum is not captured without a suitable introduction of perturbations to the flow field or the ignition model.

Mainly these rather practical limitations prevent LES currently from being applied in the predicted way [12], though it is generally accepted that it is a potentially more predictive modelling approach. An important step forward would therefore be further development and introduction of the already mentioned perturbation models for the flow field and/or the boundaries in order to run the engine cycles mostly in parallel instead of successively. In combination with a steadily increasing computing power, this would seem to be a promising strategy for the future.

Academic research was carried out with LES and URANS and will remain indispensable to understand the underlying mechanisms of irregular combustion. In [113] a G-equation approach was coupled with detailed chemistry and a fine mesh to capture detonation. In [114] turbulence/chemistry-interaction was modelled with a FGM model, [115] additionally applied the Bradly-detonation criterion and therefore evaluated the detonation intensity. In [116] a statistical RANS-PDF knock model was proposed that introduced additional equations for mixture fraction and enthalpy variance. Robert used the Bradley criterion for a simulation of 15 LES-cycles [117]. The same number of LES cycles was applied to different knocking engine operating points in $[46,118]$.

During the last decade, a lot of research work was done in the field of pre-ignitions, i.e., mixture ignition prior to spark discharge followed by a heavy knock-event. These events appear stochastically after several seconds or even minutes at high engine load which excludes a mechanism that solely depends on cycle-to-cycle variations. Experimental observations suggested that fuel/oil (gasoline engines), oil droplets (gas engines), or deposits from oil/fuel residuals that are detached from the combustion chamber walls initiate the combustion [119-122]. Though models and workflows were suggested in the past on the basis of the CFD-simulation [123], the information of the wall wetting, oil accumulation, and deposit formation over several thousands of engine cycles is missing and a fully comprehensive modelling approach is not in reach at the moment for this problem.

\section{Emissions}

\subsection{Hydrocarbons}

Hydrocarbon or HC emissions result from flame extinction at cylinder walls, crevices, and very lean mixture regions. They are therefore relevant for gas and dual fuel engines. Generally, the prediction of HC emissions addresses two of the previously mentioned limits of the methodology, namely the cycle-to-cycle variations and the wall temperatures.

The slow-burning cycles are particularly relevant for $\mathrm{HC}$ emissions. Similar to the issue of the knocking combustion, this immediately brings up the discussion of how a multi-cycle simulation approach with LES represents these cycles at the very border of the cycle spectrum.

The flame quenching at the cylinder walls depends on the heat transfer in the thermal wall layer. This requires an accurately modelled temperature gradient at the wall and the local wall temperature. The lube oil film on the liner may influence flame quenching. All these details are usually not included in CFD-models with the necessary accuracy, and the simulation of $\mathrm{HC}$ emissions must be currently considered from a rather qualitative than a quantitative point of view.

A recent demonstration of the present capabilities was given by Kuppa et al., who presented results of a URANS simulation including a flame quenching model based on the Péclet-number, a crevice and post oxidation model and found a good qualitative agreement with measurements from a 1-cylinder research engine [102]. 


\subsection{Nitric Oxides}

Nitric oxide formation can be categorized in thermal NO (Zeldovich), prompt NO (Fenimore), and $\mathrm{NO}$ from $\mathrm{N}_{2} \mathrm{O}$. Thermal $\mathrm{NO}$ is the most important contribution and based on the endothermic reaction of nitrogen and oxygen with intermediates like $\mathrm{O}$, $\mathrm{OH}$, and $\mathrm{N}$. Prompt $\mathrm{NO}$ depends on the presence of $\mathrm{CH}$ in fuel-rich regions of the diesel spray, while $\mathrm{NO}$ from $\mathrm{N}_{2} \mathrm{O}$ contributes at lower temperatures and high pressure as they prevail in the lean burning gas and dual fuel engines. Generally, NO emissions can be modelled and predicted in a reasonable way [94] and were already successfully applied to large bore diesel engines [124]. The chemical time scales are large compared to the turbulent time scales, i.e., $D a$-numbers are small, and the turbulence/chemistry interaction can be neglected in many cases. From this follows, that NO emissions do not have the same sensitivity on mixture inhomogeneity, boundary conditions and CCV as $\mathrm{HC}$ or soot emissions. The chemical mechanisms of NO formation are comparably well understood, and the size of the mechanisms allows an application in CFD-codes. The most critical prerequisites are the correct simulation of air entrainment in the diesel spray and the local temperatures. Therefore, numerous publications are available that show good correlations of URANS CFD-simulations with measurement results. Many papers documented that $\mathrm{NO}_{\mathrm{x}}$ emissions can be reasonably predicted with less detailed simulation methods like reactor models or 0D-simulations.

Figure 7 illustrates the results of the simulated $\mathrm{NO}_{\mathrm{x}}$ emissions for the dual fuel engine that was already described in Figures 1, 2, and 6. The nitric oxide reaction rates were modelled with an extended Zeldovich-mechanism. Figure 7a shows a comparison between measured and simulated NOx emissions for significantly different diesel substitution and EGR rates. In spite of the differences between measurement and simulation that can be observed for the individual operating points, it can be stated that the overall trend is well captured by the CFD-simulation when keeping the complexity of the combustion process in mind. Nitric oxide emissions are primarily formed during the combustion of the diesel fuel at high temperatures and close to the stoichiometric equivalence ratio. Therefore, $\mathrm{NO}_{\mathrm{x}}$ emissions increase when injecting diesel with $5 \%$ of the overall fuel energy instead of $1 \%$. At the third operating point, the very high amount of diesel fuel is balanced with $20 \%$ residual gas. This lowers the oxygen concentration and extends the ignition delay and the combustion process. The $\mathrm{NO}_{x}$ formation is in the same order as for the $1 \%$ diesel pilot injection due to the lower temperature and the reduction of the reactive species oxygen.

Figure $7 \mathrm{~b}$ shows iso-surfaces of the nitric oxide mole fractions at a crank angle of $10^{\circ}$ after TDC. The reduced formation of NOx, especially in the center of the combustion chamber, is clearly noticeable for $20 \%$ fuel energy from diesel.

As a conclusion, it can be stated that the mechanisms of NO formation are better understood than most other features within a typical engine simulation including spray formation and turbulent combustion. Therefore, if the simulation of the NO emissions does not match the experiments the problems frequently are to be found elsewhere.

\subsection{Soot and Particles}

Soot and particle formation are mainly topics of diesel engines. The challenge to model particle formation embraces detailed chemistry analyses in order to capture all precursors and intermediates as well as physical processes like coagulation, condensation, collision, agglomeration, surface adsorption and desorption of the reactants. A problem-inherent limit of the prediction comes from the fact that the soot mass during an engine cycle usually changes over several magnitudes. A considerable amount of soot is formed in the rich mixture of the ignited diesel spray, and afterwards oxidized to a value very close to zero, i.e., the outcome of the simulation is the difference of two quantities, namely soot formation and oxidation, which have almost the same value. Minor errors in the prediction of soot formation or oxidation inevitably result in a large error of engine-out that might reach a magnitude or more [49]. This issue is related to the process rather than to the modelling 
approach, and even relative evaluations between different measures and operating points seem currently problematic.

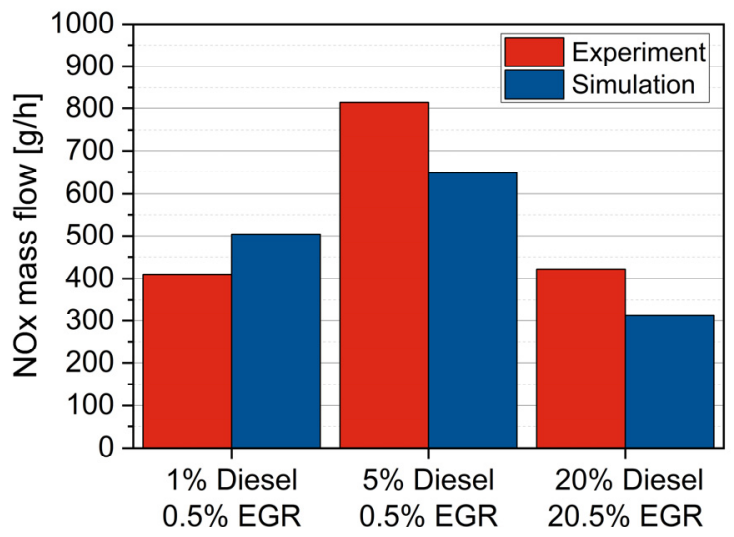

(a)

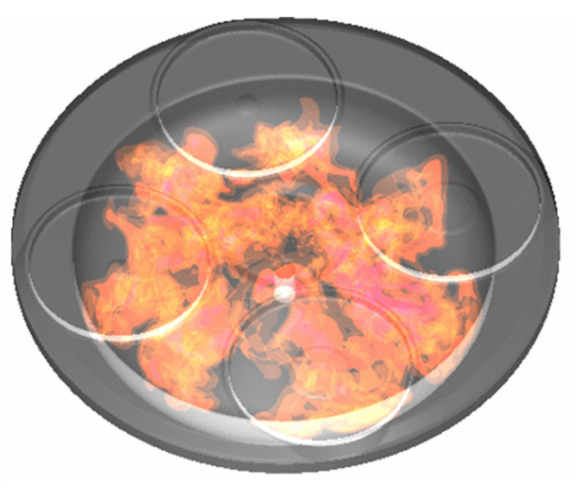

5\% Diesel, $0.5 \%$ EGR

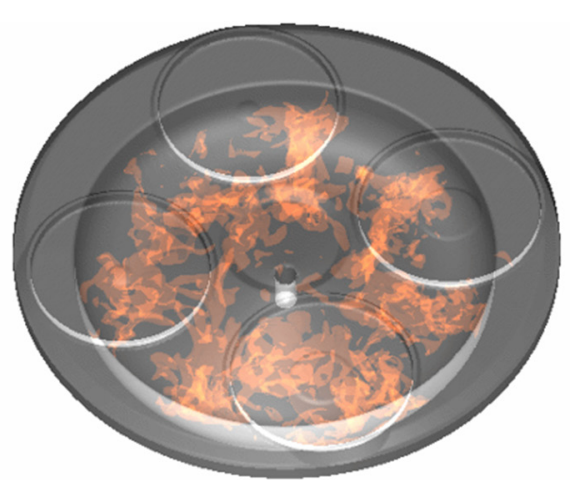

$20 \%$ Diesel, 20.5\% EGR

(b)

Figure 7. (a) Comparison of simulated and measured $\mathrm{NO}_{\mathrm{x}}$ emissions for a large dual fuel engine with different diesel substitution and EGR rates; (b) nitric oxide iso-surfaces at $10^{\circ} \mathrm{CA}$ after TDC.

Soot models usually take detailed chemistry into account in order to capture the presence of precursor species like $\mathrm{C}_{2} \mathrm{H}_{2}$ and $\mathrm{C}_{3} \mathrm{H}_{3}$. Soot oxidation is proposed as $\mathrm{O}_{2}$ and $\mathrm{OH}$ adsorption on the surface of the soot particle, mobility on the particle surface and possibility to change the site, soot oxidation, and desorption of carbon monoxide [125,126]. Methods to predict particle size distribution were introduced as flow field post processing routines involving unsteady flamelet modelling. The evolution of the particle size distribution function (PSDF) was described with a sectional method or transport equations of the first two moments of the PSDF [127,128]. While soot mass and number is modelled with transport equations in [129], detailed chemical mechanisms are usually applied to soot formation. In [130] URANS and LES are combined with a $\mathrm{C}_{2} \mathrm{H}_{2}$-formulation and compared to the results from spray A investigations. Both approaches identified the position of the soot cloud correctly. LES additionally described the non-equilibrium soot formation and oxidation. In [131] a n-heptane mechanism was coupled with a reduced polycyclic aromatic hydrocarbon chemistry mechanism in order to capture the impact of soot precursors. Ferrara et al. investigated in [132] the soot formation from oxymethylene ether-3 in premixed burner flames using a conditional quadrature method of moments and confirmed the observation of many engine tests, namely that the particle number and soot mass is strongly reduced compared to diesel fuel $[133,134]$. 


\section{Conclusions}

It was the aim of this paper to present a summary of the present CFD simulation methods for in-cylinder modelling with a focus on combustion processes relevant for large engines. It was emphasized that simplifications and assumptions are inherent to turbulence, spray, and combustion models due to the non-deterministic nature of turbulent flow. Further uncertainties result from the boundary conditions that are not known in necessary detail like the cylinder wall temperatures and the variations coming from ignition and injection. Although there are many examples of a successful application of the models to engine processes, experience, model adaption, and a careful interpretation of the simulation results will remain necessary. Research and development contributions are frequently made to specific combustion or emission models while accepting the simplifications of the models "upstream" like turbulence and spray. Therefore, the tuning of a given model always comprises the deficiencies of the complete setup including turbulence, spray, and combustion.

LES resolves the large turbulent structures and sustains the stochastic nature of the turbulent flow to some degree. It theoretically enables the analysis of cycle-to-cycle variations of the engine process, which is important for the prediction of kinetically controlled processes like irregular combustion or pollutant formation in dual fuel or gas engines. The model assumptions involved are therefore less fundamental than for URANS. LES is therefore frequently regarded as a considerable step towards predictive modelling. However, in spite of its undoubted advantages with respect to the prediction of the turbulent flow field and the turbulence/chemistry-interaction, and although efforts were taken to promote opportunities to establish this methodology in an industrial context [135], an increased application of LES or even VLES to industrial development processes as indicated in [12] has not been observed so far. The fact that LES still requires the modelling of the processes on the subgrid scales partially weakens the benefits, particularly when coupled with spray and combustion models. The uncertainties of the boundary conditions remain and the unknown perturbations of the injection or ignition system in combination with a limited number of simulated cycles may result in an incomplete representation of the engine cycle spectrum. Particularly, the dramatically increased numerical effort due to the necessity to simulate a sufficient number of engine cycles in order to obtain the required statistical information is currently the most severe drawback of LES. Research on the perturbation of the flow field and/or the boundary conditions seems to be a very promising approach to strongly parallelize the simulation and to cut down the number of working cycles that must be run consecutively. This may bring scale-resolving methods much closer to the requirements of an industrial development process.

On the other hand, numerous examples demonstrated during the last years that URANS can be applied successfully to the combustion process of large engines and even knocking combustion can be analyzed in a qualitative sense. It goes without saying that for the URANS approach a higher amount of modelling assumptions and validation will remain necessary, whose validity is strongly depending on the users' expertise.

From an industry point of view, the further application and acceptance of simulation methods will be strongly interlaced with the future of the internal combustion engine itself and the funding and budgets that will be granted for its further development. The agreement to decarbonize the traffic and energy sector by 2050 that was concluded at the climate conference in Paris 2015 questioned the sustainability of all $\mathrm{CO}_{2}$-emitting processes. More and more stringent regulations with respect to pollutant emissions and an extension of emission protected areas worldwide will further increase the pressure on large engines. Alternative power sources like fuel cells or pure electric propulsion for short-distance shipping will become more attractive in a technical and economic sense. Advanced combustion processes like dual fuel combustion with sustainable hydrogen and diesel combustion with $\mathrm{CO}_{2}$-neutral liquid fuels like oxymethylene ethers and multi-injection will have to be introduced on a large scale in order to keep the internal combustion engine competitive. Therefore, the development of tailor-made chemical mechanisms and combustion models 
that account for complex mixing of different fuels and products will remain important tasks. From this follows that a variety of turbulence and combustion models will have to be available in commercial codes in order to exploit their specific capabilities with respect to a given combustion process and to support the engines' development process with CFD in the best possible way. This should be promoted by close cooperation of research institutions, suppliers of commercial numerical codes, and engine manufacturers.

Although there will remain restrictions in the near future with respect to fully predictive and versatile numerical methods, there is no reason to disregard the achievements that were reached in the field of combustion modelling. Turbulent combustion must be considered as one of the most demanding tasks in computational engineering. The American Nobel Prize Laureate for Physics Richard Feynman once described turbulence as "the most important unsolved problem of classical physics" because a description of the phenomenon from first principles does not exist. It must not be forgotten that CFD simulations provided insight in turbulent in-cylinder flow, mixture formation, combustion, and pollutant formation that could not be delivered by pure experiments. Such outcomes have been undoubtedly one of the major progresses in the past few decades in the field of internal combustion engines and will contribute to further development in the future if the social framework allows it.

Author Contributions: Conceptualization, T.L.; methodology, T.L.; validation, J.F., T.L.; formal analysis, J.F.; investigation, T.L., J.F.; writing-original draft preparation, T.L.; writing-review and editing, T.L.; visualization, J.F., T.L.; supervision, T.L.; project administration, T.L.; funding acquisition, T.L. All authors have read and agreed to the published version of the manuscript.

Funding: Parts of this work were funded by Österreichische Forschungsförderungsgesellschaft in the framework of the BRIDGE-project "DualFlame", grant number 850690.

Acknowledgments: The authors would like to thank Stefano Fontanesi, Alessandro d'Adamo, Rolf D. Reitz, Christian Hasse, Reinhard Tatschl, Peter Priesching, Yuri M. Wright and Norbert Zöbinger for the discussions and inputs, Andreas Wimmer for his support of the paper release, and TU Wien Bibliothek for financial support through its Open Access Funding Program. The computational results presented have been achieved using the Vienna Scientific Cluster (VSC).

Conflicts of Interest: The authors declare no conflict of interest.

\section{References}

1. Lauer, T. Towards Prediction of Turbulent Combustion and Pollutant Formation?-Current Modelling Approaches with a Focus on Large Engines. In Proceedings of the 17th Conference the Working Process of the Internal Combustion Engine, Graz, Austria, 26 September 2019.

2. $\mathrm{CO}_{2}$ Emission Performance Standards for Cars and Vans (2020 Onwards). Available online: https://ec.europa.eu/clima/policies / transport/vehicles/regulation_en (accessed on 17 October 2020).

3. Towards a Climate-Neutral Germany-Three Steps for Achieving Climate Neutrality by 2050 and an Intermediate Target of $-65 \%$ in 2030 as Part of the EU Green Deal. Available online: https://www.agora-energiewende.de/en/publications/towards-aclimate-neutral-germany-executive-summary / (accessed on 4 October 2020).

4. Pope, S.B. Turbulent Flows; Cambridge University Press: Cambridge, UK, 2011.

5. Ferziger, J.H.; Perić, M. Computational Methods for Fluid Dynamics; Springer: Berlin/Heidelberg, Germany, 2002.

6. Schmitt, M.; Frouzakis, C.E.; Tomboulides, A.G.; Wright, Y.M.; Boulouchos, K. Direct numerical simulation of the effect of compression on the flow, temperature and composition under engine-like conditions. Proc. Combust. Inst. 2015, 35, 3069-3077. [CrossRef]

7. Schmitt, M.; Frouzakis, C.E.; Wright, Y.M.; Tomboulides, A.; Boulouchos, K. Direct numerical simulation of the compression stroke under engine relevant conditions: Local wall heat flux distribution. Int. J. Heat Mass Transf. 2016, 92, 718-731. [CrossRef]

8. Benekos, S.; Frouzakis, C.E.; Giannakopoulos, G.K.; Bolla, M.; Wright, Y.M.; Boulouchos, K. Prechamber ignition: An exploratory 2-D DNS study of the effects of initial temperature and main chamber composition. Combust. Flame 2020, 215, 10-27. [CrossRef]

9. Shepherd, I.; Moss, J.; Bray, K. Turbulent transport in a confined premixed flame. Symp. Int. Combust. 1982, 19, 423-431. [CrossRef]

10. Oefelein, J.C. Large eddy simulation of turbulent combustion processes in propulsion and power systems. Prog. Aerosp. Sci. 2006, 42, 2-37. [CrossRef]

11. Rutland, C. Large-eddy simulations for internal combustion engines-A review. Int. J. Engine Res. 2011, 12, 421-451. [CrossRef]

12. Hasse, C. Scale-resolving simulations in engine combustion process design based on a systematic approach for model development. Int. J. Engine Res. 2015, 17, 44-62. [CrossRef] 
13. Merker, G.P.; Schwarz, C.; Teichmann, R. (Eds.) Simulation of Combustion and Charging. In Combustion Engines Development: Mixture Preparation, Combustion, Emissions and Simulation; Springer: Berlin/Heidelberg, Germany, 2011.

14. Ilie, M. Numerical studies of turbulent swirling reacting flows using LES and URANS. Int. J. Therm. Sci. 2018, 134, 89-100. [CrossRef]

15. Zöchbauer, M.; Smith, H.; Lauer, T. Advanced SCR Flow Modeling with a Validated Large Eddy Simulation; SAE Technical Paper Series; SAE Technical Paper 2015-01-1046; SAE International: Warrendale, PA, USA, 2015.

16. Nemati, A.; Ong, J.C.; Jensen, M.V.; Pang, K.M.; Mayer, S.; Walther, J.H. Numerical Study of the Scavenging Process in a Large Two-Stroke Marine Engine Using URANS and LES Turbulence Models; SAE Technical Paper Series; SAE Technical Paper 2020-01-2012; SAE International: Warrendale, PA, USA, 2020.

17. Hemmingsen, C.S.; Ingvorsen, K.M.; Mayer, S.; Walther, J.H. LES And URANS simulations of the swirling flow in a dynamic model of a uniflow-scavenged cylinder. Int. J. Heat Fluid Flow 2016, 62, 213-223. [CrossRef]

18. Yang, X.; Gupta, S.; Kuo, T.-W.; Gopalakrishnan, V. RANS and Large Eddy Simulation of Internal Combustion Engine Flows-A Comparative Study. J. Eng. Gas Turbines Power 2014, 136, 051507. [CrossRef]

19. Liu, K.; Haworth, D. Large-Eddy Simulation for an Axisymmetric Piston-Cylinder Assembly with and Without Swirl. Flow Turbul. Combust. 2010, 85, 279-307. [CrossRef]

20. Baum, E.L.; Peterson, B.; Surmann, C.; Michaelis, D.; Böhm, B.; Dreizler, A. Investigation of the 3D flow field in an IC engine using tomographic PIV. Proc. Combust. Inst. 2013, 34, 2903-2910. [CrossRef]

21. Schiffmann, P.; Gupta, S.; Reuss, D.L.; Sick, V.; Yang, X.; Kuo, T.-W. TCC-III Engine Benchmark for Large-Eddy Simulation of IC Engine Flows. Oil Gas Sci. Technol. Rev. 2015, 71, 3. [CrossRef]

22. Reuss, D.L.; Zhong, Z.; Yang, X.; Kuo, T.-W.; Sick, V. Measured and LES Motored-Flow Kinetic Energy Evolution in the TCC-III Engine; SAE Technical Paper Series; SAE International: Warrendale, PA, USA, 2018. [CrossRef]

23. Ko, I.; Rulli, F.; Fontanesi, S.; D'Adamo, A.; Min, K. Methodology for the large-eddy simulation and particle image velocimetry analysis of large-scale flow structures on TCC-III engine under motored condition. Int. J. Engine Res. 2020. [CrossRef]

24. Krastev, V.K.; D’Adamo, A.; Berni, F.; Fontanesi, S. Validation of a zonal hybrid URANS/LES turbulence modeling method for multi-cycle engine flow simulation. Int. J. Engine Res. 2019, 21, 632-648. [CrossRef]

25. Goryntsev, D.; Sadiki, A.; Klein, M.; Janicka, J. Large eddy simulation based analysis of the effects of cycle-to-cycle variations on air-fuel mixing in realistic DISI IC-engines. Proc. Combust. Inst. 2009, 32, 2759-2766. [CrossRef]

26. Postrioti, L.; Paltrinieri, S.; Tiberi, A.; D'Adamo, A. LES Multi-Cycle Analysis of a High Performance GDI Engine; SAE Technical Paper Series; SAE International: Warrendale, PA, USA, 2013. [CrossRef]

27. Brußies, E. Simulation der Zylinderinnenströmung eines Zweiventil-Dieselmotors mit Einem Skalenauflösenden Turbulenzmodell. Ph.D. Thesis, TU Darmstadt, Darmstadt, Germany, 2013.

28. Angelberger, C.; Poinsot, T.; Delhay, B. Improving Near-Wall Combustion and Wall Heat Transfer Modeling in SI Engine Computations; SAE Technical Paper Series; SAE International: Warrendale, PA, USA, 1997. [CrossRef]

29. Keum, S.; Park, H.; Babajimopoulos, A.; Assanis, D.N.; Jung, D. Modelling of heat transfer in internal combustion engines with variable density effect. Int. J. Engine Res. 2011, 12, 513-526. [CrossRef]

30. Berni, F.; Cicalese, G.; Fontanesi, S. A modified thermal wall function for the estimation of gas-to-wall heat fluxes in CFD in-cylinder simulations of high performance spark-ignition engines. Appl. Therm. Eng. 2017, 115, 1045-1062. [CrossRef]

31. Šarić, S.; Basara, B.; Suga, K.; Gomboc, S. Analytical Wall-Function Strategy for the Modelling of Turbulent Heat Transfer in the Automotive CFD Applications; SAE Technical Paper Series; SAE International: Warrendale, PA, USA, 2019. [CrossRef]

32. Šarić, S.; Basara, B.; Gomboc, S.; Pavlović, Z. Towards Mesh Independent Modeling of Convective Heat Transfer in IC Engines; IMEM: Detroit, MI, USA, 2019.

33. Mandanis, C.; Schmitt, M.; Koch, J.; Wright, Y.M.; Boulouchos, K. Wall Heat Flux and Thermal Stratification Investigations during the Compression Stroke of an engine-like Geometry: A comparison between LES and DNS. Flow Turbul. Combust. 2017, 100, 769-795. [CrossRef]

34. Wu, A.; Keum, S.; Sick, V. Large Eddy Simulations with Conjugate Heat Transfer (CHT) modeling of Internal Combustion Engines (ICEs). Oil Gas Sci. Technol. Rev. 2019, 74, 51. [CrossRef]

35. Cicalese, G.; Berni, F.; Fontanesi, S.; D'Adamo, A.; Andreoli, E. A Comprehensive CFD-CHT Methodology for the Characterization of a Diesel Engine: From the Heat Transfer Prediction to the Thermal Field Evaluation; SAE Technical Paper Series; SAE International: Warrendale, PA, USA, 2017; Volume 1. [CrossRef]

36. Leguille, M.; Ravet, F.; Le Moine, J.; Pomraning, E.; Richards, K.; Senecal, P.K. Coupled Fluid-Solid Simulation for the Prediction of Gas-Exposed Surface Temperature Distribution in a SI Engine; SAE Technical Paper Series; SAE International: Warrendale, PA, USA, 2017; Volume 1. [CrossRef]

37. Ameen, M.; Som, S. Capturing Cyclic Variability in SI Engines with High-Fidelity LES Using a New Parallel Perturbation Approach; IMEM: Detroit, MI, USA, 2017.

38. Ameen, M.M.; Yang, X.; Kuo, T.-W.; Som, S. Parallel methodology to capture cyclic variability in motored engines. Int. J. Engine Res. 2016, 18, 366-377. [CrossRef]

39. Probst, D.; Wijeyakulasuriya, S.; Pal, P.; Kolodziej, C.; Pomraning, E. Accelerating Computational Fluid Dynamics simulations of Engine Knock using a Concurrent Cycles Approach. In Proceedings of the ASME 2020 Internal Combustion Engine Fall Technical Conference, Denver, CO, USA, 4 November 2020. 
40. Jupudi, R.S.; Finney, C.E.; Primus, R.; Wijeyakulasuriya, S.; Klingbeil, A.E.; Tamma, B.; Stoyanov, M. Application of High Performance Computing for Simulating Cycle-to-Cycle Variation in Dual-Fuel Combustion Engines; SAE Technical Paper Series; SAE International: Warrendale, PA, USA, 2016; Volume 1. [CrossRef]

41. Yue, Z.; Hessel, R.; Reitz, R.D. Investigation of real gas effects on combustion and emissions in internal combustion engines and implications for development of chemical kinetics mechanisms. Int. J. Engine Res. 2018, 19, 269-281. [CrossRef]

42. Yue, Z.; Reitz, R.D. Numerical investigation of radiative heat transfer in internal combustion engines. Appl. Energy 2019, 235, 147-163. [CrossRef]

43. Aronsson, U.; Solaka, H.; Lequien, G.; Andersson, Ö.; Johansson, B. Analysis of Errors in Heat Release Calculations Due to Distortion of the In-Cylinder Volume Trace from Mechanical Deformation in Optical Diesel Engines. SAE Int. J. Engines 2012, 5, 1561-1570. [CrossRef]

44. Figer, G.; Schmidleitner, K.; Schönbacher, M.; Kammerdiener, T. 300 bar Peak Firing Pressure for a New Generation of Diesel and Gas Engines. MTZ Worldw. 2019, 80, 66-71. [CrossRef]

45. Priesching, P.; Bogensperger, M.; Pavlović, Z.; Tatschl, R.; Vitek, O.; Božek, J. Tracking Cycle to Cycle Variations in a Gasoline DI Engine by Applying LES Combustion Modeling; IMEM: Detroit, MI, USA, 2012.

46. D'Adamo, A.; Breda, S.; Fontanesi, S.; Cantore, G. LES Modelling of Spark-Ignition Cycle-to-Cycle Variability on a Highly Downsized DISI Engine. SAE Int. J. Engines 2015, 8, 2029-2041. [CrossRef]

47. Goryntsev, D.; Sadiki, A.; Janicka, J. Investigation of Fuel-Air Mixing in DISI Engine using LES; SAE Technical Paper Series; SAE Technical Paper 2011-01-1886; SAE International: Warrendale, PA, USA, 2011.

48. Reitz, R.D. Mechanism of atomization of a liquid jet. Phys. Fluids 1982, 25, 1730. [CrossRef]

49. Stiesch, G. Modeling Engine Spray and Combustion Processes; Springer: Berlin/Heidelberg, Germany, 2003.

50. Jiang, X.; Siamas, G.A.; Jagus, K.; Karayiannis, T.G. Physical modelling and advanced simulations of gas-liquid two-phase jet flows in atomization and sprays. Prog. Energy Combust. Sci. 2010, 36, 131-167. [CrossRef]

51. Haworth, D.C. A Review of Turbulent Combustion Modeling for Multidimensional In-Cylinder CFD; SAE Technical Paper Series; SAE Technical Paper 2005-01-0993; SAE International: Warrendale, PA, USA, 2005.

52. Steiner, R.; Bauer, C.; Krüger, C.; Otto, F.; Maas, U. 3D-Simulation of DI-Diesel Combustion Applying a Progress Variable Approach Accounting for Complex Chemistry; SAE Technical Paper Series; SAE Technical Paper 2004-01-0106; SAE International: Warrendale, PA, USA, 2004. [CrossRef]

53. Pandal, A.; García-Oliver, J.; Pastor, J.M. Eulerian CFD modeling of nozzle geometry effects on ECN Sprays A and D: Assessment and analysis. Int. J. Engine Res. 2019, 21, 73-88. [CrossRef]

54. Agarwal, A.; Trujillo, M.F. High Fidelity Simulations of Nozzle Internal Flow and its Effect on Breakup Behavior; IMEM: Detroit, MI, USA, 2019.

55. Li, H.; Rutland, C. Uncertainty Quantification of Direct Injection Diesel and Gasoline Spray Simulations; SAE Technical Paper Series; SAE Technical Paper 2017-01-0836; SAE International: Warrendale, PA, USA, 2017; Volume 1. [CrossRef]

56. Meyer, G.; Gschirr, A. Fundamental Aspects and Progress in Initial Flame Kernel Modeling for Modern Modulated Capacity Discharge High-Energy Ignition Systems. In Proceedings of the 15th Conference the Working Process of the Internal Combustion Engine, Graz, Austria, 24 September 2015.

57. Schirru, A.; Irimescu, S.; Merola, A.; d'Adamo, S. Fontanesi, Flame Kernel Growth and Related Effects of Spark Plug Electrodes: Fluid Motion Interaction in an Optically Accessible DISI Engine. Int. J. Mech. Mechatron. Eng. 2020, 14, 95-103.

58. Pei, Y.; Hawkes, E.R.; Kook, S.; Goldin, G.M.; Lu, T. Modelling n-dodecane spray and combustion with the transported probability density function method. Combust. Flame 2015, 162, 2006-2019. [CrossRef]

59. Bolla, M.; Chishty, M.A.; Hawkes, E.R.; Kook, S. Modeling combustion under engine combustion network Spray A conditions with multiple injections using the transported probability density function method. Int. J. Engine Res. 2017, 18, 6-14. [CrossRef]

60. Han, K.; Seo, J.; Huh, K.Y. Lagrangian conditionalmoment closure model with flame group interaction for lifted turbulent spray jet flames. Combust. Theory Model. 2017, 21, 419-439. [CrossRef]

61. Borghesi, G.; Mastorakos, E.; Devaud, C.B.; Bilger, R.W. Modeling evaporation effects in conditional moment closure for spray autoignition. Combust. Theory Model. 2011, 15, 725-752. [CrossRef]

62. De Paola, G.; Mastorakos, E.; Wright, Y.M.; Boulouchos, K. Diesel Engine Simulations with Multi-Dimensional Conditional Moment Closure. Combust. Sci. Technol. 2008, 180, 883-899. [CrossRef]

63. Stanković, I. Modelling of non-premixed turbulent combustion with Conditional Moment Closure (CMC). Eur. Phys. J. E 2018, 41, 150. [CrossRef]

64. Kahila, H.; Wehrfritz, A.; Kaario, O.; Masouleh, M.G.; Maes, N.; Somers, L.; Vuorinen, V. Large-eddy simulation on the influence of injection pressure in reacting Spray A. Combust. Flame 2018, 191, 142-159. [CrossRef]

65. Andree, S.; Goryntsev, D.; Theile, M.; Henke, B.; Schleef, K.; Nocke, J.; Tap, F.; Buchholz, B.; Hassel, E. Numerical Simulation of a Large Bore Dual Fuel Marine Engine Using Tabulated Detailed Reaction Mechanisms; ASME: Chicago, IL, USA, 2019. [CrossRef]

66. Seddik, O.; Pandurangi, S.; Bolla, M.; Boulouchos, K.; Srna, A.; Wright, Y.M. Flamelet Generated Manifolds Applied to Dual-Fuel Combustion of Lean Methane/Air Mixtures at Engine Relevant Conditions Ignited by $n$ Dodecane Micro Pilot Sprays; SAE Technical Paper Series; SAE Technical Paper 2019-01-1163; SAE International: Warrendale, PA, USA, 2019. [CrossRef]

67. Som, S.; Aggarwal, S. Effects of primary breakup modeling on spray and combustion characteristics of compression ignition engines. Combust. Flame 2010, 157, 1179-1193. [CrossRef] 
68. Li, H.; Rutland, C.; Im, H.; Perez, F.H. Large-Eddy Simulation of Turbulent Dispersion Effects in Direct Injection Diesel and Gasoline Sprays. SAE Int. J. Adv. Curr. Prac. Mobil. 2019, 1, 675-690. [CrossRef]

69. Kundu, P.; Ameen, M.M.; Som, S. Importance of turbulence-chemistry interactions at low temperature engine conditions. Combust. Flame 2017, 183, 283-298. [CrossRef]

70. Pucilowski, M.; Jangi, M.; Fatehi, H.; Pang, K.M.; Bai, X. LES Study of Diesel Flame/Wall Interaction and Mixing Mechanisms at Different Wall Distances. In Proceedings of the Combustion Institute; 2020; in press. [CrossRef]

71. De Villiers, E.; Gosman, A.; Weller, H. Large Eddy Simulation of Primary Diesel Spray Atomization; SAE Technical Paper Series; SAE International: Warrendale, PA, USA, 2004; Volume 1. [CrossRef]

72. Hasse, C.; Barths, H.; Peters, N. Modelling the Effect of Split Injections in Diesel Engines Using Representative Interactive Flamelets; SAE Technical Paper 1999-01-3547; SAE: Warrendale, PA, USA, 1999; Volume 1, p. 3547.

73. Naber, J.D.; Sieber, D.L. Effects of Gas Density and Vaporization on Penetration and Dispersion of Diesel Sprays; SAE Technical Paper 960034; SAE: Warrendale, PA, USA, 1996.

74. Yue, Z.; Reitz, R.D. An equilibrium phase spray model for high-pressure fuel injection and engine combustion simulations. Int. J. Engine Res. 2019, 20, 203-215. [CrossRef]

75. Wang, Y.; Ge, H.-W.; Reitz, R.D. Validation of Mesh- and Timestep- Independent Spray Models for Multi-Dimensional Engine CFD Simulation. SAE Int. J. Fuels Lubr. 2010, 3, 277-302. [CrossRef]

76. Gong, C.; Jangi, M.; Bai, X.-S. Large eddy simulation of n-Dodecane spray combustion in a high pressure combustion vessel. Appl. Energy 2014, 136, 373-381. [CrossRef]

77. Frassoldati, A.; D’Errico, G.; Lucchini, T.; Stagni, A.; Cuoci, A.; Faravelli, T.; Onorati, A.; Ranzi, E. Reduced kinetic mechanisms of diesel fuel surrogate for engine CFD simulations. Combust. Flame 2015, 162, 3991-4007. [CrossRef]

78. Novella, R.; García, A.; Pastor, J.M.; Domenech, V. The role of detailed chemical kinetics on CFD diesel spray ignition and combustion modelling. Math. Comput. Model. 2011, 54, 1706-1719. [CrossRef]

79. Eder, L.; Ban, M.; Pirker, G.; Vujanović, M.; Priesching, P.; Wimmer, A. Development and Validation of 3D-CFD Injection and Combustion Models for Dual Fuel Combustion in Diesel Ignited Large Gas Engines. Energies 2018, 11, 643. [CrossRef]

80. Henke, B.; Andree, S.; Buchholz, B.; Theile, M. Pilot Injection Strategies for Medium-speed Dual-fuel Engines. MTZ Ind. 2018, 8, 48-55. [CrossRef]

81. Schuh, S.; Frühhaber, J.; Lauer, T.; Winter, F. A Novel Dual Fuel Reaction Mechanism for Ignition in Natural Gas-Diesel Combustion. Energies 2019, 12, 4396. [CrossRef]

82. Chung, W.T.; Ma, P.C.; Ihme, M. Examination of diesel spray combustion in supercritical ambient fluid using large-eddy simulations. Int. J. Engine Res. 2019, 21, 122-133. [CrossRef]

83. Perini, F.; Busch, S.; Reitz, R. An Investigation of Real-Gas and Multiphase Effects on Multicomponent Diesel Sprays. SAE Int. J. Adv. Curr. Prac. Mobil. 2020, 2, 1774-1785. [CrossRef]

84. Zöbinger, N.; Lauer, T. Numerical Investigation of the Influence of Oil Dilution on the Ability to Initiate a Pre-Ignition Combustion. SAE Int. J. Adv. Curr. Prac. Mobil. 2020, 2, 1935-1962. [CrossRef]

85. Del Pecchia, M.; Fontanesi, S. A methodology to formulate multicomponent fuel surrogates to model flame propagation and ignition delay. Fuel 2020, 279, 118337. [CrossRef]

86. Xu, C.; Pal, P.; Ren, X.; Sjoberg, M.; Van Dam, N.; Wu, Y.; Lu, T.; McNenly, M.J.; Som, S. Numerical Investigation of Fuel Property Effects on Mixed-Mode Combustion in a Spark-Ignition Engine. J. Energy Resour. Technol. 2020, 1-13. [CrossRef]

87. Frühhaber, J.; Peter, A.; Schuh, S.; Lauer, T.; Wensing, M.; Winter, F.; Priesching, P.; Pachler, K. Modeling the Pilot Injection and the Ignition Process of a Dual Fuel Injector with Experimental Data from a Combustion Chamber Using Detailed Reaction Kinetics; SAE Technical Paper 2018-01-1724; SAE: Warrendale, PA, USA, 2018; Volume 1, p. 1724.

88. Pregger, T.; Schiller, G.; Cebulla, F.; Dietrich, R.-U.; Maier, S.; Thess, A.D.; Lischke, A.; Monnerie, N.; Sattler, C.; Le Clercq, P.; et al. Future Fuels-Analyses of the Future Prospects of Renewable Synthetic Fuels. Energies 2019, 13, 138. [CrossRef]

89. Wermuth, N.; Lackner, M.; Barnstedt, K.D.; Wimmer, A.; Url, M.; Fimml, W. Hydrogen/Methanol and Hydrogen/Diesel Dual Fuel Combustion Systems for Sustainable Maritime Applications; Rostocker Großmotorentagung: Rostock, Germany, 2020.

90. Lee, B.; Ge, H.; Parameswaran, S.; Zhao, P. CFD Simulation of a Premixed Spark Injection Hydrogen Engine. In Proceedings of the ASME 2019 Internal Combustion Engine Division Fall Technical Conference, Chicago, IL, USA, 20-23 October 2019.

91. Gaukel, K.; Pélerin, D.; Härtl, M.; Wachtmeister, G. The Fuel OME2: An Example to Pave the Way to Emission-Neutral Vehicles with Combustion Engine. In Proceedings of the 37th international Vienna motor symposium, Vienna, Austria, $28-29$ April 2016.

92. Lumpp, B.; Rothe, D.; Pastötter, C.; Lämmermann, R.; Jacob, E. Oxymethylene ethers as diesel fuel additives of the future. MTZ Worldw. 2011, 72, 34-38. [CrossRef]

93. Peters, N. Turbulent Combustion; Cambridge University Press: Cambridge, UK, 2000.

94. Warnatz, J.; Maas, U.; Dibble, R.W. Combustion; Springer: Berlin/Heidelberg, Germany, 2006.

95. Buschmann, A.; Dinkelacker, F.; Schäfer, T.; Schäfer, M.; Wolfrum, J. Measurement of the instantaneous detailed flame structure in turbulent premixed combustion. In Symposium (International) on Combustion; Elsevier: Amsterdam, The Netherlands, 1996; pp. 437-445. Available online: https://www.sciencedirect.com/science/article/abs/pii/S0082078496802463 (accessed on 10 October 2020).

96. Han, W.; Wang, H.; Kuenne, G.; Hawkes, E.R.; Chen, J.H.; Janicka, J.; Hasse, C. Large eddy simulation/dynamic thickened flame modeling of a high Karlovitz number turbulent premixed jet flame. Proc. Combust. Inst. 2019, 37, 2555-2563. [CrossRef] 
97. Colin, O.; Benkenida, A. The 3-Zones Extended Coherent Flame Model (Ecfm3z) for Computing Premixed/Diffusion Combustion. Oil Gas Sci. Technol. Rev. 2004, 59, 593-609. [CrossRef]

98. Lehtiniemi, H.; Mauss, F.; Balthasar, M.; Magnusson, I. Modeling diesel spray ignition using detailed chemistry with a progress variable approach. Combust. Sci. Technol. 2006, 178, 1977-1997. [CrossRef]

99. Kösters, A.; Karlsson, A.; Oevermann, M.; D’Errico, G.; Lucchini, T. RANS predictions of turbulent diffusion flames: Comparison of a reactor and a flamelet combustion model to the well stirred approach. Combust. Theory Model. 2015, 19, 81-106. [CrossRef]

100. Wehrfritz, A.; Kaario, O.; Vuorinen, V.; Somers, B. Large Eddy Simulation of n-dodecane spray flames using Flamelet Generated Manifolds. Combust. Flame 2016, 167, 113-131. [CrossRef]

101. Rodatz, P.; Weisser, G.; Tanner, F.X. Assessment of CFD Methods for Large Diesel Engines Equipped with a Common Rail Injection System; SAE Technical Paper Series; SAE International: Warrendale, PA, USA, 2000.

102. Kuppa, K.; Nguyen, H.; Goldmann, A.; Korb, B.; Wachtmeister, G.; Dinkelacker, F. Numerical modelling of unburned hydrocarbon emissions in gas engines with varied fuels. Fuel 2019, 254, 115532. [CrossRef]

103. Kuppa, K.; Goldmann, A.; Schöffler, T.; Dinkelacker, F. Laminar flame properties of C1-C3 alkanes/hydrogen blends at gas engine conditions. Fuel 2018, 224, 32-46. [CrossRef]

104. Martinez-Morett, D.; Tozzi, L.; Marchese, A.J. A Reduced Chemical Kinetic Mechanism for CFD Simulations of High BMEP, Lean-Burn Natural Gas Engines. In Proceedings of the ASME 2012 Internal Combustion Engine Division Spring Technical Conference, Torino, Piemonte, Italy, 6-9 May 2012; pp. 61-71.

105. Xu, G.; Wright, Y.M.; Schiliro, M.; Boulouchos, K. Characterization of combustion in a gas engine ignited using a small unscavenged pre-chamber. Int. J. Engine Res. 2018, 21, 1085-1106. [CrossRef]

106. Winter, H.; Schneßl, E.; Pirker, G.; Zelenka, J.; Wimmer, A. Application of CFD simulation to optimize combustion in Prechamber gas engines with port injection. In Proceedings of the 7th European Conference on Computational Fluid Dynamics, Glasgow, UK, 11-15 June 2018.

107. Decan, G.; Lucchini, T.; D'Errico, G.; Verhelst, S. A novel technique for detailed and time-efficient combustion modeling of fumigated dual-fuel internal combustion engines. Appl. Therm. Eng. 2020, 174, 115224. [CrossRef]

108. Wang, H.; Gan, H.; Theotokatos, G. Parametric investigation of pre-injection on the combustion, knocking and emissions behaviour of a large marine four-stroke dual-fuel engine. Fuel 2020, 281, 118744. [CrossRef]

109. Wijeyakulasuriya, S.; Jupudi, R.S.; Givler, S.; Primus, R.J.; Klingbeil, A.E.; Raju, M.; Raman, A. Multidimensional Modeling and Validation of Dual-Fuel Combustion in a Large Bore Medium Speed Diesel Engine. In Proceedings of the ASME 2015 Internal Combustion Engine Division Fall Technical Conference, V001T01A006, Houston, TX, USA, 11 November 2015.

110. Frankl, S.; Gleis, S.; Wachtmeister, G. Interpretation of Ignition and Combustion in a Full-Optical High- Pressure-Dual-Fuel (HPDF) Engine using 3D-CFD Methods. In Proceedings of the 29th CIMAC World Congress, Vancouver, BC, Canada, 10 June 2019.

111. Eder, L.; Kiesling, C.; Pirker, G.; Priesching, P.; Wimmer, A. 3D-CFD Simulation of Dual Fuel Combustion in a Diesel Ignited Gas Engine; IMEM: Detroit, MI, USA, 2017.

112. Som, S.; Senecal, P.K.; Pomraning, E. Comparison of RANS and LES Turbulence Models against Constant Volume Diesel Experiments, ILASS Americas. In Proceedings of the 24th Annual Conference on Liquid Atomization and Spray Systems, San Antonio, TX, USA, 20-23 May 2012.

113. Pal, P.; Wu, Y.; Lu, T.; Som, S.; See, Y.C.; Le Moine, A. Multidimensional Numerical Simulations of Knocking Combustion in a Cooperative Fuel Research Engine. J. Energy Resour. Technol. 2018, 140, 102205. [CrossRef]

114. Goryntsev, D.; Tap, F.; Tvrdojevic, M.; Priesching, P. SI Engine Combustion and Knock Modelling Using Detailed Fuel Surrogate Models and Tabulated Chemistry; SAE Technical Paper 2019-01-0205; SAE International: Warrendale, PA, USA, 2019.

115. Netzer, C.; Seidel, L.; Pasternak, M.; Lehtiniemi, H.; Perlman, C.; Ravet, F.; Mauss, F. Three-dimensional computational fluid dynamics engine knock prediction and evaluation based on detailed chemistry and detonation theory. Int. J. Engine Res. 2018, 19, 33-44. [CrossRef]

116. D'Adamo, A.; Breda, S.; Berni, F.; Fontanesi, S. The potential of statistical RANS to predict knock tendency: Comparison with LES and experiments on a spark-ignition engine. Appl. Energy 2019, 249, 126-142. [CrossRef]

117. Robert, A.; Richard, S.; Colin, O.; Poinsot, T. LES study of deflagration to detonation mechanisms in a downsized spark ignition engine. Combust. Flame 2015, 162, 2788-2807. [CrossRef]

118. Chen, C.; Pal, P.; Ameen, M.; Feng, D.; Wei, H. Large-eddy simulation study on cycle-to-cycle variation of knocking combustion in a spark-ignition engine. Appl. Energy 2020, 261, 114447. [CrossRef]

119. Dahnz, C.; Spicher, U. Irregular combustion in supercharged spark ignition engines-pre-ignition and other phenomena. Int. J. Engine Res. 2010, 11, 485-498. [CrossRef]

120. Zahdeh, A.; Rothenberger, P.; Nguyen, W.; Anbarasu, M.; Schmuck-Soldan, S.; Schaefer, J.; Goebel, T. Fundamental Approach to Investigate Pre-Ignition in Boosted SI Engines. SAE Int. J. Engines 2011, 4, 246-273. [CrossRef]

121. Yasueda, S.; Takasaki, K.; Hiroshi, T. The Abnormal Combustion Caused by Lubricating Oil on High BMEP Gas Engines. In Proceedings of the 13th Conference the Working Process of the Internal Combustion Engine, Graz, Austria, 22 September 2011.

122. Yasueda, S.; Zhu, S.; Sotiropoulou, E.; Tozzi, L. The investigation of the abnormal combustion by lubricating oil with the advanced CFD simulation. In Proceedings of the 15th Conf the Working Process of the Internal Combustion Engine, Graz, Austria, 24 September 2015. 
123. Lauer, T.; Heiss, M.; Bobicic, N.; Holly, W. A Comprehensive Simulation Approach to Irregular Combustion; SAE Technical Paper 2014-01-1214; SAE International: Warrendale, PA, USA, 2014.

124. Najar, I.; Stengel, B.; Buchholz, B.; Hassel, E. Pilot Injection and Thermal Nitrogen Oxides: A Numerical and Experimental Study. SAE Int. J. Engines 2020, 13, 473-486. [CrossRef]

125. Frenklach, M.; Wang, H. Detailed Mechanism and Modeling of Soot Particle Formation. In Soot Formation in Combustion; Bockhorn, H., Ed.; Springer: Berlin/Heidelberg, Germany, 1994; pp. 165-192.

126. Mauss, F.; Trilken, B.; Breitbach, H.; Peters, N. Soot formation in Partially Premixed Diffusion Flames. In Soot Formation in Combustion; Bockhorn, H., Ed.; Springer: Berlin/Heidelberg, Germany, 1994; pp. 325-349.

127. Netzell, K.; Lehtiniemi, H.; Mauss, F. Calculating the soot particle size distribution function in turbulent diffustion flames using a sectional method. Proc. Combust. Inst. 2007, 31, 667-674. Available online: https://www.sciencedirect.com/science/article/abs/ pii/S1540748906003440 (accessed on 10 October 2020). [CrossRef]

128. Frenklach, M. Method of moments with interpolative closure. Chem. Eng. Sci. 2002, 57, 2229-2239. [CrossRef]

129. Pang, K.M.; Karvounis, N.; Walther, J.H.; Schramm, J. Numerical investigation of soot formation and oxidation processes under large two-stroke marine diesel engine-like conditions using integrated CFD-chemical kinetics. Appl. Energy 2016, 169, 874-887. [CrossRef]

130. Farrace, D.; Sakellarakis, D.; Bolla, M.; Wright, Y.M.; Boulouchos, K. Numerical Investigations of Soot Dynamics at Engine-Relevant Conditions; SAE Technical Paper 2018-01-0204; SAE International: Warrendale, PA, USA, 2018.

131. Vishwanathan, G.; Reitz, R.D. Development of a Practical Soot Modeling Approach and Its Application to Low-Temperature Diesel Combustion. Combust. Sci. Technol. 2010, 182, 1050-1082. [CrossRef]

132. Ferraro, F.; Russo, C.; Schmitz, R.; Hasse, C.; Sirignano, M. Experimental and numerical study on the effect of oxymethylene ether-3 (OME3) on soot particle formation. Fuel 2021, 286, 119353. [CrossRef]

133. Härtl, M.; Seidenspinner, P.; Jacob, E.; Wachtmeister, G. Oxygenate screening on a heavy-duty diesel engine and emission characteristics of highly oxygenated oxymethylene ether fuelOME1. Fuel 2015, 153, 328-335. [CrossRef]

134. Avolio, G.; Kastner, O.; Rösel, G.; Brück, R. The Influence of Synthetic Fuels on the Emissions of Diesel Engines. MTZ Worldw. 2018, 79, 16-23. [CrossRef]

135. Leudesdorff, W.; Unger, T.; Janicka, J.; Hasse, C. Scale-resolving Simulations for Combustion Process Development. MTZ Worldw. 2019, 80, 62-67. [CrossRef] 